\title{
STRATEGIC INTERACTION: DISTRUST AND COOPERATION \\ IN US-CHINA RELATIONS
}

BY

SHANE DAVID WILCOX

\author{
A thesis \\ submitted to the Victoria University of Wellington \\ in partial fulfilment of the requirements for the degree of \\ Master of Strategic Studies
}

Victoria University of Wellington 


\section{Abstract}

International cooperation is generally thought to be made possible, or at least enhanced, by a relationship of trust between nations. This proposition is examined with a particular focus on US-China relations, and proceeds through a critique of various models of cooperation that works to expose the limits imposed by the assumption of a causal relationship between trust and cooperation.

A concept of strategic interaction is developed on the basis of analysis of values and interests, asymmetric exchange and distrust, and is offered as an alternative to grand strategic narratives for understanding the strategic behaviour of states. 


\section{Acknowledgements}

First thanks must go to my wife, Juliet Bergh, for making all things possible and for having to put up with rather too much during the writing of this thesis.

Secondly, to Professor Robert Ayson, my supervisor, for his guidance and enthusiasm. And probably also for having to put up with rather too much. 
Table of contents

\begin{tabular}{|c|c|c|}
\hline Abstract & 2 & \\
\hline Acknowledgements & 3 & \\
\hline Introduction & 8 & \\
\hline America's China dilemma & 10 & $\begin{array}{l}\text { America and China are engaged in the single } \\
\text { most important bilateral relationship in the in- } \\
\text { ternational system at the present time. Rivalry } \\
\text { between these great powers risks devolving into } \\
\text { open conflict, the repercussions of which would } \\
\text { have potentially devastating global implications. } \\
\text { If these outcomes are to be avoided, it seems } \\
\text { clear that US-China interactions should be guid- } \\
\text { ed by strategies that foster cooperation, but it is } \\
\text { less clear how such strategies should be formu- } \\
\text { lated and enacted. }\end{array}$ \\
\hline Cooperation under anarchy & 18 & $\begin{array}{l}\text { When the US-China relationship is modelled as a } \\
\text { classical prisoners' dilemma, cooperation seems } \\
\text { destined to fail, but extending the analysis of this } \\
\text { game-theoretical model through its temporal } \\
\text { dimension and payoff structure opens the ques- } \\
\text { tion of what may constitute cooperation beyond } \\
\text { the confines of a formalized game. }\end{array}$ \\
\hline Values and interests & 23 & $\begin{array}{l}\text { Central to this question is the complex relation- } \\
\text { ship between the values, perceptions and actions } \\
\text { of each player, which are manifest as competing } \\
\text { interests when players engage, resulting in stress- } \\
\text { es on their respective value systems. }\end{array}$ \\
\hline $\begin{array}{l}\text { Strategic relationships 1: the } \\
\text { US-Soviet example }\end{array}$ & 26 & $\begin{array}{l}\text { Perhaps the starkest example of this process is in } \\
\text { the Cold War competition between America and } \\
\text { the Soviet Union, resulting in the collapse of one } \\
\text { value system under pressure from the other. This } \\
\text { singular strategic relationship, conflictual in } \\
\text { virtually every sense except for the most poten- } \\
\text { tially catastrophic, was predicated on distrust as } \\
\text { the very condition of the cooperation that en- } \\
\text { sured the survival of the antagonists. }\end{array}$ \\
\hline
\end{tabular}




\begin{tabular}{|l|l|l|}
\hline $\begin{array}{l}\text { Strategic relationships 2: } \\
\text { trust and cooperation }\end{array}$ & 29 & $\begin{array}{l}\text { As such, this example exposes the limits of game } \\
\text { theory-based models that assume a constitutive } \\
\text { link between cooperation and trust. }\end{array}$ \\
\hline $\begin{array}{l}\text { Exchange relationships: } \\
\text { equilibrium and asymmetry }\end{array}$ & 34 & $\begin{array}{l}\text { In contrast with this essentially conflictual, or } \\
\text { "strategic" interstate relationship, are more obvi- } \\
\text { ously cooperative, or "exchange" relationships } \\
\text { that are given to hold between states under less } \\
\text { fraught conditions of equilibrium. }\end{array}$ \\
\hline Reciprocity and strategy & 38 & $\begin{array}{l}\text { Analysis of these relations under the rubric of so- } \\
\text { cial exchange theory reveals the asymmetries } \\
\text { that of necessity underlie exchanges of value, but } \\
\text { which tend to be concealed again by theories of } \\
\text { reciprocity that privilege cooperation and trust, } \\
\text { and attempt to reduce conflict to the status of an } \\
\text { unfortunate aberration, which it is the role of } \\
\text { strategy to correct. }\end{array}$ \\
\hline Strategic equilibrium: values \\
and interests redux
\end{tabular}




\begin{tabular}{|l|l|l|}
\hline $\begin{array}{l}\text { Cooperation as conflict: nar- } \\
\text { rative origins of trust and } \\
\text { distrust }\end{array}$ & 47 & $\begin{array}{l}\text { Maintaining stable interests under conditions of } \\
\text { deep instability implies that courses of action } \\
\text { taken in pursuit of interests must eventually } \\
\text { come to undermine them, in accordance with the } \\
\text { logic of strategy. Cooperation is a partial solu- } \\
\text { tion to this problem, functioning to delay the } \\
\text { point of reversal from stability to instability. If } \\
\text { the delay is of sufficient duration, cooperation in } \\
\text { a given interaction may become normative, gen- } \\
\text { erating narratives of trust that appear to explain } \\
\text { its occurrence, and narratives of distrust to ex- } \\
\text { plain its failure. These narratives obscure the } \\
\text { real and imaginary causal chains that run in both } \\
\text { directions between cooperation and trust, and } \\
\text { tend to reify either a simple cause and effect link, } \\
\text { or a closed loop that passes from trust to } \\
\text { cooperation. }\end{array}$ \\
\hline Distrusting narratives & 52 & $\begin{array}{l}\text { What separates these similarly flawed accounts is } \\
\text { the manner in which they engage examples of } \\
\text { cooperative behaviour, some trusting that the } \\
\text { example will simply support the theory in whose } \\
\text { name it is offered, others that the sheer number } \\
\text { of examples obviates the need for any coherent } \\
\text { theory at all. } \\
\text { that examples can either be exhausted by theory } \\
\text { or can stand in theory's place, then we resist the } \\
\text { collapse of real and imaginary, and can begin the } \\
\text { work of examining examples of interaction in } \\
\text { their strategic context. }\end{array}$ \\
\hline
\end{tabular}




\begin{tabular}{|c|c|c|}
\hline $\begin{array}{l}\text { Distrusting behaviours: real } \\
\text { and imaginary }\end{array}$ & 60 & $\begin{array}{l}\text { The first American freedom of navigation opera- } \\
\text { tion in October } 2015 \text { and the official Chinese re- } \\
\text { sponse are examples of signalling behaviour that } \\
\text { simultaneously enact the collapsing of the real- } \\
\text { imaginary distinction and resist a similar enact- } \\
\text { ment by its opposite number. Attempts to con- } \\
\text { sider these behaviours as isolated incidents ren- } \\
\text { ders them unintelligible; only as an asymmetrical } \\
\text { exchange signalling distrust do they make strate- } \\
\text { gic sense. }\end{array}$ \\
\hline $\begin{array}{l}\text { Superficial symmetry, deep } \\
\text { asymmetry }\end{array}$ & 63 & $\begin{array}{l}\text { Examined in this light, the exchange of signals } \\
\text { described here functions as an instance of co- } \\
\text { operation, being costly to either side and con- } \\
\text { tributing to the maintenance of stable uncertainty } \\
\text { in the region. While the material costs and gains } \\
\text { to each are asymmetrical, there is an apparent } \\
\text { structural symmetry to this exchange, which in- } \\
\text { forms the theories of games and reciprocity con- } \\
\text { sidered above. Nevertheless, as exchanges play } \\
\text { out, they tend towards their culminating points, } \\
\text { and distrust of the narratives generated in support } \\
\text { of exchanges exposes the underlying contradic- } \\
\text { tions in the value systems that motivate them. A } \\
\text { strategic choice is made as to whether the asym- } \\
\text { metries uncovered can support the ongoing equi- } \\
\text { librium and whether this will continue to com- } \\
\text { port with identified interests. A behavioural } \\
\text { signal is offered and responded to by an oppo- } \\
\text { nent making a similar calculated choice; whether } \\
\text { such an exchange will prove cooperative or con- } \\
\text { flictual cannot be decided in advance. Still less } \\
\text { can such choices be bound to conform to the re- } \\
\text { quirements of a grand strategy. }\end{array}$ \\
\hline $\begin{array}{l}\text { Disconclusion: culminating } \\
\text { point }\end{array}$ & 68 & \\
\hline Reference list & 70 & \\
\hline
\end{tabular}




\section{Introduction}

The problem of international cooperation is central to strategic and security studies, and is one of the axes about which fundamental debates in international relations theory turn. Few goods are achievable in the absence of cooperation, and arguably none on a scale relevant to the relationships between states. As the power of states increases, so too the difficulty in maintaining cooperation between them and the risks attendant upon failing to do so. It has become almost axiomatic that the main obstacle to greater cooperation is a lack of trust between nations, particularly between great powers, and even more particularly between great powers as the balance between them shifts. The solution to the problem of cooperation must therefore be to build trust between such states.

The relationship between China and America provides the world's primary contemporary example of this problem. The importance of trust-building between them has been declaimed by both sides under the administrations of Presidents Xi and Obama, notably in comments made by then Secretary of State Clinton in support of America's "pivot to Asia," a discussion of which opens this thesis, and on several occasions by President Xi, and reiterated at his first official meeting with Obama at Sunnylands, California, in June 2013. At the joint press conference following their summit, Xi announced his confidence in a "new model of major country relationship," in pursuit of which both nations would "need to deepen our mutual understanding, strengthen our mutual trust, further develop our cooperation and manage our differences so that we can avoid the traditional path of inevitable confrontation between major countries and really embark on a new path" (Obama \& Xi J., 2013, June 8).

Laudable as Xi's desire to skirt Thucydidean inevitabilities may be, if it is the case, as a commentator on Xi's concept asserts, that "mistrust is embedded so deeply in intellectual theories, bureaucratic understandings and interests, and popular anxieties," then the path "from the current place of mutual mistrust to circumstances that are more stable and productive" will be a crooked one indeed (Lampton, 2013, p. 57). As the old joke has it, "if that's where you're going, I wouldn't start from here." But if here is where we are, then perhaps the destination requires rethinking. In this thesis, the nature of cooperation is examined from various angles, and the causal link widely supposed to exist between cooperation and trust is questioned. A step-by-step 
summary of the argument can be found in the table of contents, and so rather than repeating that here, it may be more helpful to provide a brief comment on the argument's structure.

I take the core of all properly strategic thought to be Clausewitz's concept of the "culminating point," given more recent expression in Edward Luttwak's "paradoxical logic of strategy." This basic understanding informs, in one way or another, the elaboration of all the oppositions introduced here: trust and distrust, cooperation and conflict, symmetry and asymmetry, theory and example, narrative and behaviour, real and imaginary. But beyond this, the argument itself unfolds with an eye to the culminating point, at least as far as this is compatible (I hope) with readability. It is, therefore, rather non-linear, looping back on itself in a progressively tighter coil as oppositions discussed earlier are revisited and integrated into the next loop. All such oppositions, if pursued too far at once, are at risk of collapse as they converge on their culminating points, and the intention is to keep each in suspension as further complications are added, mirroring to some extent the manner in which the US-China relationship itself should be approached. 


\section{America's China dilemma}

In her 2011 article on "America's Pacific Century," then US Secretary of State Hillary Clinton sets out the case for the Obama government's "strategic turn to the Asia-Pacific" (Clinton, 2011, pp. 58, 63), emphasizing the importance both of the region to America, and, somewhat pointedly, of America to the region. She checks off the various elements of the "pivot" (2011, p. 63), citing current alliances and less formal arrangements with various nations in the region, and the need for both the further development of these relationships and the establishment of new ones, in a manner that appears to be policy statement, wish list and advertising campaign in equal measures. Having illustrated the breadth and depth of America's historical and future commitment to the region, Clinton turns her attention to "emerging partners," including, "of course," China. Despite being merely "one of the most prominent of these emerging partners," a splash of colour in the dense tapestry of American-Asian relations, "China represents one of the most challenging and consequential bilateral relationships the United States has ever had to manage" (2011, p. 59). Under the gentle but firm tutelage of its American steward, a recalcitrant China is to be guided towards the adoption of a mature role on the world stage, able to manage responsibly its economic and military power in cooperation with its partner-mentor. As befits a wise and kindly master, the means employed to this end are to include the acknowledgement of differences and the avoidance of unrealistic expectations, trust-building and encouragement, honesty and transparency (2011, pp. 59-60). China is asked to perform a few simple tasks in emulation of its teacher: communication of its intentions regarding military modernization and expansion, reform of its practices in respect of international intellectual property, allowing currency appreciation, and attention to the human and democratic rights of its citizens (2011, p. 60).

The curriculum in military affairs, economics and values having been introduced, Clinton reminds her most demanding pupil that others in the class vie for America's attention, and that nations such as India and Indonesia may be more willing and able to accept American guidance and reap the resulting rewards, primarily in virtue of their democratic politics (2011, pp. 60-61). Further, and as if to underscore American diplomatic flexibility and sensitivity in contrast with that of China, she highlights America's willingness to work with and bolster Asia's various multilateral regional organizations, which seek out American participation and leadership as they endeav- 
our to negotiate claims in the South China Sea and to manage their economic growth (2011, pp. 61-62). Finally, with an acknowledgment of America's military and economic might as geopolitical givens, Clinton asserts nevertheless that "our most potent asset as a nation is the power of our values," which have served to bring the US through a number of "setbacks," from each of which America has emerged stronger than before, and undergird a capacity for renewal "unmatched in modern history" (2011, p. 63). For what better and more able leader could the region wish?

A mere four months after the publication of this article, Clinton gave an address at the China Conference hosted by the U.S. Institute of Peace. While its substantive content essentially reproduces that of the earlier piece, there is a marked shift in emphasis and tone. Elements of the pedagogical approach remain, but couched now in what amounts to a complete about face in attitude. No longer the callow, brash student with potential, to be reminded of its place in the classroom, China is now perhaps the teaching assistant, still with much to learn from American values and experience in the benign exercise of power, but with whom "having that positive, cooperative, and comprehensive relationship ... is vital to every one of [America's] objectives" in the Asia-Pacific. The notion of Sino-American interdependence and therefore the necessity of cooperation in the establishment and maintenance of a mutually beneficial world order is now the dominant theme, even to the extent that America "in turn, will hear and act on those changes [China] wants from us." The primary obstacles to this cooperation are the "suspicion and mistrust" each has of the other's intentions, which must be met "head-on and constructively by creating a framework for building trust over time. That means returning to first principles of the relationship: There is no intrinsic contradiction between supporting a rising China and advancing American interests. A thriving China is good for America, and a thriving America is good for China" (Clinton, 2012).

Sufficient explanation for the difference in tone and emphasis is doubtless provided by the forum for each: a broadly conservative journal which tends to foreground the military aspects of its titular remit on the one hand, and on the other, a conference in celebration of forty years of US-China diplomacy organized by a Congress-funded institution whose stated purpose is the research and promotion of conflict resolution by peaceful means. Nevertheless, the disparity may be taken to reflect a deeper uncertainty regarding the correct American response to China's rise. Hugh 
White takes Clinton's 2012 speech to represent "the beginnings of a serious discussion about America's choices concerning China" (White, 2013a, p. 9), contrasting it with President Obama's address to the Australian Parliament in November 2011, which makes direct mention of China only briefly, but does so in a manner mirrored and extended by Clinton's almost simultaneously-appearing Foreign Policy article: "the United States has been, and always will be, a Pacific nation" with a dominant military and economic presence in the region. Cooperation with "a peaceful and prosperous" China is sought, but it is clear that this will be on American terms (Obama, 2011). For White, the contrast between these positions is a stark one. In the setting of what he assumes to be China's accelerating rise, both economically and militarily, they are fundamentally incompatible, and The China Choice with respect to them is one that cannot be long delayed. The stakes could not be higher: White sees this choice, in the final analysis, as one between peace in Asia and a war with truly global consequences.

White's argument is worth pursuing for two main reasons. First, it concerns what seems likely to be the defining interstate relationship of the twenty-first century as it pertains to the region responsible for somewhere around half the world's economic growth and trade, and a primarily maritime strategic environment of contested boundaries through which flows the economic lifeblood of much of the other half. Second, its approach is, as described by Robert Ayson, "spectacularly parsimonious," which quality has enabled it to set the terms of the debate about the future of this relationship even among those who disagree with White's conclusions (Ayson, 2013, p. 17).

White takes it for granted that China's economic expansion will continue relative to that of the US, and that the size of its economy must ultimately eclipse America's, if for no other reason than that the size of its workforce means that relatively small gains in productivity are magnified into large gains in overall GDP, even while the rate of growth slows as China's economy "matures." Everything else flows from this: White contends that China's international influence has grown in lockstep with its economy, and that the material basis for power projection both within and beyond its territory can only be bolstered by this same economic growth. Further, the more wealthy and influential China becomes, the greater will be the divergence between American and Chinese interests as China confronts the "policy dilemma" between maintaining the stable order of international relations that has enabled its growth to 
date, and the need for this order to change if this growth is to fulfil its promise as the basis for increased power in the Asia-Pacific region. White feels that the balance point between these imperatives is in the process of shifting towards the latter: China's crucial importance to the global economy means that it need no longer fear being excluded should its actions displease the US, and China may "easily imagine" that the economic heft already attained, and the influence this has bought would provide a sufficient basis for leadership of a new Asian order (White, 2013a, p. 49).

In the face of this inexorable shift in the balance of power between China and the US in Asia, White sees the realm of future possibility divided into four logical outcomes: maintenance of the status quo, already discounted as an impossibility in spite of it being desirable to all in the region except China; war, between an America in ongoing and aggressive pursuit of its claims and a resistant China; US withdrawal from Asia, leaving China to fill the vacuum; and an arrangement whereby America and China share power in Asia, to their mutual (dis)satisfaction (White, 2013a, pp. 5-6). American preferences with respect to these choices are reasonably clear. The desire for continued primacy in Asia is nakedly expressed in the statements of President Obama and Secretary of State Clinton discussed above. White shares this desire, but he is certain that it must be disappointed by a China increasingly discontented with the status quo and increasingly able to act on its displeasure. He devotes a chapter of his book to the question of the "military balance," arguing that China has probably already done enough to deny American control of the waters in its immediate vicinity, without yet being able to exert its own control. White contends that, while a true "blue water" naval capability is some way off (if ever actually achievable), and it is arguable that its pursuit will divert resources from more realistic ends, its submarine and land-based anti-ship missile systems are already able to sink enough ships within its territorial waters to prevent the assertion of hegemony by an outside power, even as its own navy and coast guard suffer a similar susceptibility, and could not, therefore, achieve the control denied to others (White, 2013a, pp. 66-67).

War with China would be an unwelcome prospect, to say the least. Victory, however that might be defined, is a far from certain outcome, and even a relatively limited armed conflict would have severe global consequences, given the importance of these two economies and their interdependence. Neither could likely suffer significant economic damage without sorely damaging the other, and the rest of the world along with 
it. Much less certain is the risk of nuclear exchange. White outlines some of the perverse incentives for the early use of nuclear weapons that are especially pertinent for China, but from which the US might not be immune (White, 2013a, pp. 75-78).

But worse even than this, if only because the outcome is left less open to chance, would be American capitulation and withdrawal from Asia, leaving itself with minimal direct influence, and China with the opportunity to exercise its own desire for regional hegemony. White feels that this is likely to be met in turn by the resistance of other Asian powers, who would seek to balance against China, again putting the world's economic engine at risk (White, 2013a, pp. 99-100). If, on the other hand, China gained hegemony in Asia, whether by force (military or economic, actual or threatened) or assent, this could in turn free its hand to reach further than its immediate environs, perhaps even into America's own sphere in Central and South America, or to begin to claim a direct interest in European affairs.

Some form of mutually cooperative arrangement between China and the US remains for White as the only outcome with a reasonable chance at ensuring the maintenance of peace and stability in Asia, and is therefore the only one both relatively desirable and possible. He does not, however, consider this outcome the most likely, for at least three reasons. First, White deems that each side considers the other to be more severely constrained by their economic interdependence and the asymmetries that would characterize any military conflict, and will therefore expect that the other will withdraw from the brink of any serious conflict (White, 2013a, p. 52). Second, he argues that there is a confusion of means and ends, particularly on the part of the US, such that primacy in Asia has become and end in itself, rather than a means to continued prosperity and security, and the promotion of American values, that may be reached by other paths (2013a, p. 104). These assumptions are fundamental to the arguments presented by Clinton and Obama regarding America's relationship with Asia, and tend, therefore, to undermine the call for cooperation they appear superficially to be making. The third, and perhaps decisive reason for the likely failure of cooperation, although White pins his hopes for the future of Asia on overcoming it, is the complicating presence of other powers in Asia. While their influence is far overshadowed by that of the main contenders at the present state of play, White's proposed solution to the problem of great power relations in Asia seems to require that certain of these others be brought into the game on an equal footing. This will be explored in 
further detail at a later point, but because White's power-sharing formulation is so firmly premised on his understanding of the structure of the primary bilateral relationship, it is important to pause and tease out his deceptively parsimonious account.

White's four potential outcomes in respect of US-China relations and their ordering in terms of what he perceives to be American preferences, fairly describes a prisoners' dilemma, the staple diet of game theory-based studies of international relations. In its most basic form, the prisoners' dilemma describes a competitive situation between a pair of opponents, each of whom must make a choice, simultaneously with the other, between a strategy of cooperation and a strategy of defection. Because the players have some interests in common, although these may be outweighed in the final outcome by their opposed interests, the prisoners' dilemma is a variable or non-zero sum game, allowing for intermediate outcomes between "winning all" and "losing all." The strategies available to each player are paired with those available to the other in a series of potential outcomes; for two players, each with a choice between two strategies, there must therefore be four possible outcomes. The value, or "payoff," of each outcome to each player is typically represented by an integer in order to facilitate simple comparison, but fundamental to the analysis of such games is that payoffs are determined by the interaction of strategies, rather than by each strategy alone. Thus, a strategy of cooperation may have a very different payoff when played against a similar strategy than when played against defection. The "payoff structure" of the game so derived will determine the order of preferences each player has with respect to the possible outcomes, and this in turn defines the type of game under consideration. In a prisoners' dilemma, the order of preferred outcomes is symmetrical for each player, and is as follows: defection while the other cooperates, mutual cooperation, mutual defection, and cooperation while the other defects. Also following from the effect of the interaction of strategies on payoffs, is that there may be a "dominant" strategy, that is, one that performs better than all available alternatives whatever one's opponent plays, but that need not (and usually will not) ensure the player's preferred outcome (Dixit \& Skeath, 1999, pp. 80-87).

As derived from White's reading of American preferences, then, the structure of the "game" between the US and China is straightforward. American "defection," represented by its attempt to maintain primacy in Asia, may be met by Chinese "cooperation," which is to say acquiescence, or it may be matched by Chinese defection, its 
resistance to continued American dominance in Asia greatly increasing the risk of war between them. Alternatively, America may choose to cooperate by relinquishing its claim to dominance, against which Chinese defection would amount to its own claim for hegemony in Asia, but with which China may also cooperate and agree to share power equally with the US in Asia. America's dominant strategy must therefore be defection, as predicted by analysis of the prisoners' dilemma: if China cooperates, the US wins the "temptation payoff" of uncontested primacy, and if China defects, the US avoids the "sucker's payoff" of unilateral withdrawal.

White is less systematic in his discussion of Chinese preferences, but what he does offer here is less than reassuring. He takes it for granted that China's most and least preferred outcomes are hegemony in Asia and continued US primacy respectively, but "we cannot be sure that [China's leaders] will settle for as little as an equal share in the leadership of Asia. We can be sure they will not settle for less." At stake for China is not merely open markets or sea lines of communication in its region, but its status as a great power: "In 1972, China tacitly relinquished its claim to great power status in Asia. Today China is strong enough to claim it back, and nothing is more important to China than that claim. If necessary, it will fight for it" (White, 2013a, p. 61). It is an open question, therefore, whether China would value the payoff from mutual cooperation more than from mutual defection. If it is indeed the case that China values nothing more than its great power status, then shared power may prove insufficient to meet this demand, and war might be preferable to perceived humiliation. The resulting "deadlock" (a game in which the values of payoffs from mutual cooperation and mutual defection are reversed with respect to those of the prisoners' dilemma) must make open conflict between the US and China all but inevitable in the absence of a unilateral American withdrawal. However, elsewhere White has suggested that there might be space for a "sequel" on China's choices, which "are very similar to America's in some ways, and are obviously just as important and in many ways just as hard. ... [B]oth would be better off forgoing dreams of primacy and accepting parity instead. But that option only exists for each of them if the other makes the same choice" (White, 2013b, p. 43).

Thus, even if White's earlier assertion proves to be exaggerated, and China does not put its status before all other considerations, his approach to the problem of power in Asia mandates pessimism. Each power must make the same choice, but the logic 
of White's argument suggests that they must almost certainly both make the "wrong" one, even as he hopes otherwise. The rhetorical strength of White's analysis, which has perhaps sacrificed subtlety for clarity, culminates in his final chapter. This takes the form of an imagined Presidential address, and serves to tighten still further the narrative arc of this vision of the near future in which outcomes are treated as if the result of a single, sweeping, grand-strategic manoeuvre. Whether China and America are engaged in a simple prisoners' dilemma, or as White intimates in his primary work, perhaps a "mixed" game of prisoners' dilemma and deadlock, each has a dominant strategy of defection, which if played must lead to heightened conflict and the distinct possibility of war. Were this White's final word on the matter, there would be little to separate his position from the offensive realism of John Mearsheimer, who sees American-led containment of China as the best, if slim, chance of avoiding war (Mearsheimer, 2014, chapter 10). However, White has discounted containment as a viable option in the face of growing Chinese power and assertiveness. Having backed himself into the corner of his own syllogism, White's only recourse is to a curiously idealistic leap towards his vision of a Concert of Asia, which serves at least two incompatible functions. First, it is a stake in the game, as the form that mutual cooperation between the US and China must take for what are essentially geopolitical reasons in White's assessment, and is therefore all but doomed by the game's structure. Second, the proposed Concert must lift China and America (along with a small handful of ancillary states) out of the game altogether if it is to avoid this structural fate, but the closed loop of White's logic affords it no means of doing so, except by the near-miraculous navigations of a "remarkable statesmanship" (White, 2013a, p. 130).

White's attempt to resolve this paradox only plunges him more deeply into it. His suggested endgame is external to the US-China relationship he has described in every way: logically, historically, geographically. The diplomatic arrangement White takes as his model was rooted, as need hardly be said, in a Europe which had just emerged from the Napoleonic wars that resulted in the defeat of a would-be hegemon over a landmass with few natural boundaries (the British Isles excepted). The five powers involved in this concert were sufficiently evenly matched, militarily and economically, as to make war between any two of them an uncertain proposition at best, but the risk to the others that a successful campaign would have posed united them all in their opposition to the aggression of any, at least for a time. But even if we grant White his 
conceit that the basis of a collaborative order can in principle be abstracted from its material conditions, setting in advance the rather arbitrary conditions that signal the end of the contest between America and China does nothing to change their mutually dominant strategy of defection. No matter how lengthy and complex the diplomatic process by which the Concert might be achieved (and White provides us with little insight into how he imagines this might go), as its end approaches, the incentive to defect increases, so as to minimize the risk of being exploited without further recourse, and to maximize the chance of exploiting one's opponent without repercussion. But if this is so, then as the negotiators approach this almost certain defection, they have the very same incentive to defect, and so on back to the opening salvo. No matter how attractive the proposition of a Concert of Asia may be, it is a goal that cannot be attained given the starting conditions that White lays out. Indeed, the more attractive it is, and the more White pleads its case as the most viable arrangement for the maintenance of peace in Asia, the less likely it becomes. The "New Order" imagined by White cannot emerge from the machinations of the old as he sees them, and cannot be imposed from above, as if by some perverse deus ex machina, without triggering the conflagration that must be avoided (White, 2013a, pp. 130-138).

\section{Cooperation under anarchy}

A cooperative outcome under these terms would appear to be a near impossibility, and White has placed himself in the unenviable position of advancing a programme he admits will likely fail. Nevertheless, there is a substantial literature on the possibility of cooperation under conditions of anarchy, a good deal of which is founded on analysis of the prisoners' dilemma. Perhaps the most famous such study is that of Robert Axelrod, whose The Evolution of Co-operation summarises research conducted in the late 1970s and early 1980s and further examines its implications. He reports on two experiments in which computer-programmed strategies for playing the prisoners' dilemma were pitted against one another in round-robin fashion. In the first, fourteen submitted programmes were to play one another in games each lasting exactly 200 rounds, these conditions being known to all competitors. If the logic that structures White's argument were to hold, it might be expected that these games would comprise 200 rounds of defection. Axelrod's experiment did not fulfil this ex- 
pectation. The strategy determined by a process of backwards induction from an endgame defection may be considered one of harm minimization: it eliminates the risk of being exploited, but at the cost of maintaining an environment of perpetual mistrust and foregoing the benefits of cooperation. It allows the game to be played safely, but not well. Axelrod's competitors aimed, for the most part, to do better than this. The best performers, when considered in aggregate across the entire competition, were "nice" strategies that would never be the first to defect, and would do so only when provoked. They differed in terms of what behaviours of an opponent would count as provocation and in how they managed retaliation, but shared this willingness to risk harm in pursuit of cooperation. There were, in this first run of the experiment, some "endgame" effects, but these were by and large restricted to the final handful of rounds, and were insufficient to negate the advantage gained by nice strategies (Axelrod, 1990, pp. 30-33).

The strategy that performed best overall, both in this experiment, and the one that followed (with sixty-two entrants, all of whom were provided with full details of the first contest, engaged in games with an unpredetermined number of rounds) was dubbed TIT-FOR-TAT. The simplest strategy submitted, it always begins by cooperating, and thereafter mimics its opponent's behaviour from the previous round. Perhaps the most striking feature of this strategy is that it never "beats" its opponent; if payoffs are assumed to be symmetrical, the best TIT-FOR-TAT can achieve is parity for persistent mutual cooperation. It risks exploitation from the beginning, but immediately punishes such opportunism. It is equally quick to forgive, and cooperation is soon rewarded. In short, it does well by helping its opponents do well, even a little better than itself, if they are sufficiently responsive to TIT-FOR-TAT's reciprocating style (Axelrod, 1990, p. 112). "Mean" (those that will defect first or without provocation) or capricious strategies (like RANDOM) tend not to do well, but they also tend to take nice, reciprocating strategies like TIT-FOR-TAT down with them. Nevertheless, TIT-FOR-TAT is robust, doing well against a wide range of opponents. Axelrod distills the results of his competitions into "four simple suggestions for how to do well in a durable iterated Prisoner's Dilemma: 1. Don't be envious. 2. Don't be the first to defect. 3. Reciprocate both cooperation and defection. 4. Don't be too clever" (Axelrod, 1990, p. 110).

"Don't be too clever": this suggestion captures much of what is vital to strategic 
thinking, the understanding that actions are interdependent in competitive situations, and that in addition to their direct effect on outcomes, actions have a communicative function. In zero-sum situations, arguably very rarely, if ever truly present in international relations, the ultimate intentions of each opponent are clear and fixed with respect to one another - there is little doubt under these circumstances as to what constitutes winning and losing. Actions will, or should be, taken in cognisance of those of the opponent, but the goal is decisive in determining what counts as a good or bad move. Therefore, the further ahead one can see and plan, the better able one is to limit an opponent's choices and broaden one's own. Under these circumstances, the communicative function of action is limited, perhaps even reduced to announcing the beginning and end of the contest. By contrast, in the prisoners' dilemma and other games described by Schelling as "mixed-motive" (Schelling, 1980, p. 89), "winning" does not necessarily imply the opponent's defeat, and the best outcome is likely to be contingent upon a degree of coordination. Communicating intentions clearly and unequivocally is most easily achieved by "declaring" a willingness to cooperate from the beginning, and by responding swiftly and consistently to the other's behaviour. Deviations from this pattern - whether by trying occasional unprovoked defections in pursuit of short-term gain, by failing to punish quickly similar such attempts on the part of one's opponent, or equally by sustaining rewards and punishments for too long in spite of changes in the other's behaviour - risk adding sufficient "noise" as to render unintelligible the message one is hoping to convey, and thereby making coordination of action all but impossible.

Under the formalized conditions of Axelrod's experiment, then, strategies for playing an iterated two-player prisoners' dilemma that are nice, reciprocating, clear and consistent, tend on the whole to do well and allow "opponents" to do well by encouraging mutual cooperation. The robustness of such strategies appears to depend on the communicativeness of actions undertaken, which should therefore be overt and timely responses to similar actions on the part of the other, leaving the minimum of opportunity for misinterpretation. Such an understanding might provide the basis for a way out of White's conundrum. He has placed the onus on America to make the first move, which would entail offering "China as much as it reasonably can to bring it to the table," which must in these terms mean more than making a merely verbal statement of intent. Some material concession that puts a significant US interest at 
risk should China choose to defect would be both necessary and sufficient to open meaningful negotiation. The significance of the concession is clearly paramount: it must represent both a potential loss to the US and suggest a reciprocal action that might be undertaken by China that places it at comparable risk and telegraphs itself as an instance of cooperation. Equally, defections must be reciprocated: "Ultimately, that means being willing to go to war" (White, 2013a, p. 163). But these general statements do not take us far beyond the formal realm, which remains dominated by the spectre of a near-impossible endgame in the Concert of Asia, and as noted, White provides few specifics regarding the moves actually available to either party. In coming to a determination concerning such specifics, at least three other interrelated parameters of an "iterated two-player prisoners' dilemma" may be considered, as the context in which the four primary characteristics of the strategy itself play out: the time dimension, the payoff structure of the game itself, and the number of players. Kenneth Oye (1985) has discussed these parameters in the context of interstate cooperation under anarchy, and his analysis provides a framework from within which we can begin to consider the true extent and complexity of White's project for Asia. Discussion here will focus on the time and payoff dimensions; suffice it to say for now that increasing the number of players adds considerably to the complexity of what follows.

Iteration of a game in multiple rounds introduces a realm of future possibility that exerts some degree of influence over the present strategic decision. As discussed above (p. 18), if a game comprises only a single round, there can be no expectation of future interactions that might offer reward for cooperation, or later punishment for defection. In the prisoners' dilemma, fear of exploitation and the tempting possibility that a defection might go unopposed by an unwary competitor, eliminates cooperation as a viable strategy for either player. A finite number of repetitions, where the endpoint is known to both players, has the effect of "collapsing" the future into the present by the process of backwards induction, producing the same effect for the series as a whole. In each case, we might say that the value (or "shadow") of the future is zero. ${ }^{1}$ For an infinite series of rounds, none can be temporally differentiated

\footnotetext{
${ }^{1}$ While this remains a logical consequence of extending a game to any finite number of rounds known to both players, Axelrod's first experiment suggests that the effect may be limited to relatively small numbers, as evidenced by the increasing tendency to defect as the
} 
from any other, and each must therefore be valued as highly as any other. For games of finite length, but where the number of rounds is not predetermined, or at least is not known to either player, the value of future payoffs is some fraction of those of the present. A future that is heavily "discounted" with respect to the present implies an expectation that the number of rounds will be small; the more closely the value of the future approximates that of the present, the longer the game is expected to be and the more attractive cooperative strategies will appear. In the second of his tournaments, Axelrod effectively determined the value of the future by setting the probability that each game would end at any given round, ensuring that it was sufficiently high that cooperative strategies would likely be successful (Axelrod, 1990, pp. 42-43). For real players, the relative value attributed to future interactions derives from a complex array of factors that are both external and internal to the game, and here it is a matter of perception rather than permutation.

For example, the future may be heavily discounted for either opponent, or both, if it appears to them that the circumstances of either (or both) are sufficiently unstable that a shift in priorities could occur such that the payoff structure of their interactions changes, making cooperation a more or less viable strategy. Unless this occurs in such a way as to bring their interests more closely into alignment, resulting in a pure coordination game, any such restructuring is far more likely than not to result in the defection of at least one of the players - there are many more ways of being in disharmony than in concert. Of particular interest to Oye is the potential for ambiguity in the definitions of cooperation and defection that may reduce the stabilizing effects of reciprocity, thus shortening the shadow of the future. In the absence of explicit and agreed-upon parameters, players may fail (or plausibly claim to fail) to recognize the nature of the other's actions, or simply fail to see them at all if processes are not transparent. Further, the flexibility of action required in order to respond quickly and clearly to the other's behaviour may be limited when players are large, complex entities like states (Oye, 1985, pp. 15-16).

final round approached. Nevertheless, the principle that the future is valued relatively less than the present under these circumstances still holds. 


\section{Values and interests}

In most of the interactions so far discussed, it has been implicit that each player is engaged in the same game, that is, their preferences are similarly arranged and that this arrangement corresponds to the formal structure of the prisoners' dilemma. While each need not attach precisely the same value to every potential outcome, they must rank their payoffs similarly if this is to be the case. This calculation is a trivial matter in formal situations, but determining the relative values of various outcomes for real players may be less straightforward. It may be less than obvious to some, for example, that America would prefer war with China over voluntary withdrawal from Asia. Each outcome would entail significant costs, but these would be rather different in kind, at least at the outset, and not easily comparable. By the same token, if China does indeed value its great power status in Asia over all other considerations, then its defection under any circumstances that do not fully satisfy this demand is all but inevitable. But values need not be so starkly opposed for players to muddy or even poison the waters. In spite of the perception that interactions are likely to be ongoing, and even if the ordinal values of payoffs are consistent and compatible, changes in the absolute values of payoffs can can be important. If the benefits of mutual defection are only marginally outweighed by those of mutual cooperation, and/or if the temptation of gain from unilateral defection is too great for either opponent, the shadow of the future may be shortened by the relative discounting of cooperation in later interactions. On the other hand, payoffs may be altered in such a way as to improve the chances of cooperation. Oye cites Robert Jervis' account of unilateral actions that can reassure opponents by increasing the costs or reducing the benefits associated with defection, and doing so in a manner visible to an opponent. These may include the acquisition and deployment of defensive over offensive armaments (assuming they can be reliably differentiated), placing troops on borders to serve as de facto hostages, or publicizing agreements such that a reputation for fair dealing is put at stake (Jervis, 1978, pp. 178-179, 186-187). Bilateral strategies may involve decomposing payoffs into multiple parts and negotiating for each sequentially, or linking separate issues in such a way that addressing one is contingent upon a cooperative outcome in another; each of these payoff adjustments invokes the time dimension by increasing the likelihood of future interactions and therefore the benefits to be accrued from present co- 
operation. Multilateral regimes may generate and institutionalize norms and wider understandings that are internalized by individual states, changing perceptions of their interests and the means required to achieve them, as well as those of other states (Oye, 1985, pp. 10-11). It is also argued, if not entirely convincingly, that the "game-changing" effect of certain military technologies, in particular nuclear weapons, has been to so elevate the benefits of cooperation and diminish the chances of success of unilateral defection that the interactions between nuclear powers have mutated from prisoners' dilemmas into stag hunts (in which cooperation is the dominant strategy), or even into pure coordination, for the more optimistic (Oye, 1985, p. 9).

As already noted, changes affecting one variable (say, in the relative discount applied to the future) will produce a change in the other (the relative weighting or even the ordering of preferences), and vice versa. However, the relationship between these changes is not linear, for two primary reasons. The first of these is a deeper implication of Axelrod's “don't be too clever" rule, which might be taken to read: "no matter how far you can see, there's always someone blocking the view." This corresponds to what Edward Luttwak (2001) has termed "the paradoxical logic of strategy": in any conflictual relationship, even where this involves some degree of cooperation, the actions of one come up against the active opposition, total or partial, of the other. This logic provides the founding principle for any number of the commonplaces of strategic thought, from such apparently self-contradictory pronouncements as "if you want peace, prepare for war," to the security dilemma, to nuclear deterrence, and to the prisoners' dilemma itself. As a result, there is a tendency for the effects of those actions eventually to be reversed, to a degree and with a speed depending on the nature of the opposition and the persistence with which the action is pursued. The opposing reaction will itself suffer a similar fate, and so on, in a potentially endless recursion. In this way, while the decomposition of payoffs, for example, may improve the chances of ongoing cooperation in part by reducing the costs associated with an instance of unrequited cooperation, by so increasing the value and likelihood of future interactions, it equally reduces the risk that an ongoing interaction will be completely derailed by an isolated defection, thereby increasing the temptation to try one's luck. The second reason for the non-linear relationship between variables is that the interdependence between the payoff and time parameters is, as we have seen, mediated by that between perceptions and values. 
Certain effects of the interdependence between values and perceptions are themselves paradoxical. Values, whatever their specific content, tend to be relatively stable, and may indeed be considered eternal by those holding them, regardless of the historical evidence as to their eventual mutability. Their endurance derives from the primary function of values: to motivate action; to stand, in the end, as the reasons for actions. A single value may function in many, but not all, contexts, some of which demand the application of competing, even frankly contradictory values. Any given value can, in principle, be held alongside others with which it might appear to be incompatible, available to be called upon as circumstances dictate. For example, conformity with traditions may be valued alongside individual freedom, each motivating actions that might appear on the face of it to undermine the other. But what seems at first to be an obstacle to their integration in fact facilitates their operation as a valuesystem that, as a whole, acquires a universalizing authority in virtue of this capacity to contain contradictions in such a way as to make them appear merely superficial. One's actions, and those of others, are perceived as if framed by this motivating system of reasons, which structures and limits the interpretive possibilities from which the meanings of actions are given. The system of values is itself reinforced and extended by making sense of perceptions whose meanings are incorporated into the framework by this circularity of cause and effect. The more extensive the system becomes, and the more that incompatible values are mutually reinforced, the narrower the range of meanings that can be attributed to an action will be. This will therefore have a conservative effect on the revaluations of future discounts and payoff structures that characterize persistent interactions between real competitors, gradually raising the threshold for what will count as evidence to the contrary of increasingly reified and generalized beliefs. However, it is in precisely this situation, when one value system engages another in strategic contest, that the seeming stability and robustness of each is revealed as its greatest weakness.

In the context of such an engagement, of which we continue for now to conceive as an iterated mixed-motive game, the valuations of future and payoffs are manifest as interests, which will be congruent with those of the opponent to a greater or lesser degree, and more or less threatened by them. The pressures exerted by the other will be unevenly distributed in accordance with their interests, influencing the prioritization of certain of one's interests over others as those pressures are met, which will in turn 
affect the distribution of pressure exerted against the other, and so on. Depending on the stakes of the game and the player-states involved, these pressures will take various forms, whether diplomatic, economic, military or sociocultural, but aimed always at effecting such a revaluing of interests in the other while resisting such changes in one's own. This will be the case whether one's strategy, broadly conceived, is one of cooperation or defection, but the amount, type and points of application of pressure required will vary depending on the opponent's strategy and the particular interests involved. Where the interests of respective states are more deeply conflicting, and the pressures of opposition and resistance are correspondingly higher, certain interests initially declared by a state may give way entirely as unsustainable, merely unnecessary, or even antithetical to the developing strategic project, and be succeeded by others. As certain values are increasingly called upon in support of interests under intensifying pressure, the actions motivated in support of those interests become more and more likely to run counter to other, incommensurate values with which they have been reconciled in the system of interpretation and reinforcement. The more rigid this system has become in its accommodation of contradictory values, and the narrower the range of actions and interpretations it can therefore support, the greater the risk that such actions will be rendered uninterpretable or even irrational from the perspective it grants. If these actions are nevertheless undertaken in defence of endangered interests, they expose the value system to the risk of failure in its task of making sense of and guiding action in the world, and may ultimately trigger its collapse.

\section{Strategic relationships 1: the US-Soviet example}

In highly schematic terms, this model may provide for one understanding of the rise and demise of the Soviet Union. In the course of its various transformations from Marxist revolution to Leninist state to Stalinist empire, the fundamental contradiction, of a state apparatus founded on the principle of control of the means of economic and political production by labour, but manifested in totalitarian repression by a small and powerful elite, could be reconciled only in the context of a project of continuous expansion, culminating in global revolution and the "return" of the state to the workers. All meanings generated by the state were bent to this purpose: all the privations inflicted upon its people, the subjugation of surrounding states, the concentration of power 
ultimately in a single figure, took their moral force from the value attributed to the worker, to anti-imperialism and to equality. Failure of the expansion of this "revolution" beyond eastern Europe, the Caucasus and central and north-east Asia (the occasional appearance of an allied communist state beyond these boundaries notwithstanding) in the face of US-led containment on the one hand, and rivalry with a nominally ideologically aligned China on the other, could not but lead, at the very least, to a calling into question of its ideological underpinnings and with them the entire state apparatus geared towards continued pursuit of this moribund interest. The implicit acknowledgement of this unsustainable contradiction gave rise to the policies of political openness and economic restructuring (perestroika and glasnost) which served, in the end, only to drive wedges into the cracks already opening in critically overburdened Soviet values.

Such a dramatic reversal, occurring over such a short interval, may prove to be so exceptional an example of this process as to resist generalization. Indeed, there was little in this scenario and its context that was not unique: the relationship between the US and the USSR all but defined global international relations in terms of the politics of bipolarity, between powers whose value systems were given to be diametrically opposed at every level, and whose influence was such that it was necessary to plead a special case for "non-alignment." But it is precisely the overwhelming singularity of the relationship and the preoccupations it engendered that gave rise to the very modes of thought by which we generate our understandings of the strategic relationships between states even now. And it is for these reasons that we may take the US-USSR relationship to be the primary example, perhaps the only example, of a "purely" strategic one. Whatever the historical accuracy in its minutiae, this relationship has been cast almost exclusively in Manichaean terms since soon after the Second World War, both by those responsible for the generation and enactment of policy concerning the relationship, and by those who would theorize about its implications. This "Cold War mentality" was both the context and the very reason for the inauguration of strategic studies as a discipline, and so this relationship, thought of in this way, has become a kind of yardstick by which other interstate relations, particularly those between the US and would be rivals and competitors including China, are measured.

The US-Soviet relationship, then, has been considered an essentially oppositional one. Each state took as foundational a value system that came increasingly to be de- 
fined against that of the other, there was very little trade or cultural exchange between them, alliances were arranged with the express purpose of thwarting the interests of the other, and their militaries, conventional and otherwise, were designed primarily to function as deterrents against one another, or should this fail, to have the capacity, by one means or another, to retaliate decisively. These conditions would appear to mandate a zero-sum approach to considerations of the outcome of any given interaction. Their interests being so completely opposed, any gain by one must be seen as a loss to the other, and at no point could one trust the other to make any move that would not be to its detriment. But in the developing context of a nuclear weapons doctrine that assured mutual destruction in the event of direct armed conflict, the paramount interest of each, its own survival, became interdependent. With each state posing the only plausible threat to the survival of the other, at the same time each became, as the mechanism of this logic played out, the only plausible threat to itself. Such circumstances were arguably sufficient to raise the probability of cooperation on the avoidance of armed conflict to near certainty. With everything at stake, the shadow of the future would be lengthened indefinitely over mutual survival, but cast so narrowly as to exclude all other interests from its shelter. In the pursuit of these subordinate interests, by contrast, there was little incentive to risk exploitation and every encouragement to chance the win, so long as neither overstepped this single bound. The prevailing atmosphere of distrust and defection made it all the more necessary that actions in respect of the development, testing, deployment and posture of nuclear weapons conform more or less with Axelrod's "rules" regarding transparency and reciprocity. The correct interpretation of and responses to these actions were in this sense absolutely predicated on distrust: if other interests came to be seen to overlap to some significant degree such that one could no longer be certain that one's actions were not in some way benefiting the other, and vice versa, the reduction in pressure exerted upon those interests and the admission that perhaps, under some circumstances, the other could be trusted, the risk might have been that the imperative to clarity of statement and to the unambiguous reciprocation of action and reaction on the nuclear stage could be relaxed. Any lessening of the fear that a "wrong move" might trigger a fatal response would correspondingly increase the temptation to hedge and dissemble in order to gain the upper hand, in the hope that one might blur or cross certain lines unnoticed. It is worth considering, at least in this instance that most 
closely approximates a pure strategic relationship, that such cooperation as there was, sufficient at least to prevent a nuclear catastrophe, could have occurred only on the basis of complete mutual distrust. ${ }^{2}$

\section{Strategic relationships 2: trust and cooperation}

This admittedly counterintuitive claim flies in the face of a long held and oft-repeated assumption regarding the necessary relationship between trust and cooperation, particularly when, as in the interactions between states, there is no external arbiter to enforce compliance with agreements. So inseparable are they considered that Andrew Kydd can define them only in a perfectly circular manner:

$[T]$ rust is a belief that the other side prefers mutual cooperation to exploiting one's own cooperation, while mistrust is a belief that that the other side prefers exploiting one's cooperation to returning it.... Cooperation between two actors will be possible if the level of trust each has for the other exceeds some threshold specific to the situation and the actors (Kydd, 2005, p. 6).

The remainder of his book is, in essence, a sophisticated game theoretical explication of this tautology, on the basis of which it is shown that states can engage in cooperative relationships only to the extent that they are able to reassure others that they are sufficiently trustworthy, which they achieve in the main by sending "costly signals" that they are willing to cooperate. On Kydd's reading, the end of the Cold War

\footnotetext{
${ }^{2}$ Recent events in Ukraine may be interpreted in light of the period of lessening distrust between the US and Russia following the demise of the USSR. The eastward expansion of NATO into what had been Soviet territory constitutes, at the very least, an instance of ambiguous signalling regarding potentially hostile intentions. Successive enlargements were themselves met by rather muted responses until the 2008 Russo-Georgian war, but this appears to have been insufficient to fully restore the distrust between Russia and the USNATO alliance to prevent similarly ambiguous overtures to Ukraine. The Russian annexation of Crimea was decisive, but characterized almost as the return of a territorial loan. The initiation and ongoing support for separatist movements in eastern Ukraine was conducted in such a manner as to provide for (im)plausible deniability - hardly the clear responses that would once have been demanded and expected. While Russia's diminished status and economic dependence on Europe make it very unlikely that the relationship between the US and Russia will again become a purely strategic one, it is to be hoped that a measure of distrust be restored, sufficient to reduce the risk of direct conflict and potential for escalation.
} 
came about as a result of Gorbachev's ability to reassure Reagan and then Bush that the USSR no longer posed an expansionist threat. A costly signal indeed, the dissolution of the Soviet empire and ultimately of the state itself into fragmentary independent republics, and seemingly unnecessary given the warm reception with which the Soviet decommissioning of some 1,846 intermediate-range missiles (as against the 848 surrendered by the Americans) under the terms of the 1987 INF Treaty was received, not to mention the Soviet withdrawal from Afghanistan, the massive troop reductions in Eastern Europe, and the liberalization of domestic politics, all in 1988 (2005, pp. 227-233). State suicide, even, and perhaps especially, if not quite intentional, seems on the contrary a rather abject gesture, far more likely to elicit triumphalism and ridicule, or at the very least Schadenfreude, than trust. Such gross overdetermination suggests that what remains beyond the tight loop formed by trust and cooperation, which is to say everything that "exceeds some threshold specific to the situation and the actors," is, in fact, everything, or at least everything that is pertinent to any given instance of cooperation.

Aaron Hoffman makes the case for decoupling trust from cooperation, noting that in presupposing the necessity of the link between them, one "winds up overestimating the incidence of trusting relationships, implying, for instance, that trust operates even when cooperation is coerced" (Hoffman, 2002, p. 376). Like Kydd, Hoffman considers various definitions of trust, but plumps for what he calls the "fiduciary approach": trust entails "confidence in expectations that others will 'do what is right"," combining "the concept of obligation with the idea that trust involves risk. Trust involves more than predicting the behaviour of others. It includes trustors' perceptions that their trustees have a responsibility to fulfill the trust placed in them even if it means sacrificing some of their own benefits" (2002, p. 379). He argues that such a definition usefully excludes certain cases of cooperation, such as the avoidance of direct conflict between the US and USSR during the Cold War, from the category of trusting relationships on the grounds that neither believed the other was under any obligation to refrain from defection, despite the fact that the survival of each was to at least some degree in the hands of the other (2002, p. 381). Hoffman goes on to counter the objection that the obligation implied by this definition of trust is incompatible with self-interest, citing the establishment of international institutions and norms by self-interested state actors that assume such obligations (2002, pp. 
383-384). Leaving aside the question this begs regarding the self-interestedness of trusting states, he turns to making his definition operational for the task of identifying those examples of cooperation that are based on trusting relationships.

Three parameters are developed according to which the degree of trust underlying an instance of cooperation might be measured. The most "sensitive" of these measures "involves (1) identifying policies that grant other states discretion over outcomes previously controlled by the first and (2) demonstrating that the leaders responsible for enacting such policies did so at least in part because they believed that their counterparts were trustworthy" (Hoffman, 2002, p. 385). Such discretion having been granted, the second parameter is a consideration of the mechanisms by which its exercise is monitored. The more leeway granted the trustee by the oversight mechanism, the greater the degree of trust implied. Such oversight may be applied either before or after the decisions of trustee states are implemented, aimed respectively at preventing and punishing unwanted behaviour. After-the-fact oversight, by means of "fire alarm"-type mechanisms among others, tends to be less resource-intensive and more efficient, but is obviously reactive and offers the monitored state considerable freedom of action. Before-the-fact oversight, provided by "police patrols" and the like, is intended to discern the antecedents of defection, and must therefore be both more intensive and more invasive, potentially imposing significant costs of various types on all parties to an agreement, and clearly allowing relatively less leeway to the state under sanction (2002, pp. 388-389). Hoffman argues that "all agreements contain at least the potential for overseeing and sanctioning actor performance," whether these mechanisms are made explicit or remain implicit, and that the examination of such arrangements for before- and after-the-fact monitoring assist in determining the level of trust between states, especially where there is a change from one type of oversight to the other (2002, pp. 390-391). Where agreements are codified in written form, the types of rules according to which states are expected to act provide the basis for the third parameter for the assessment of trust. Hoffman distinguishes between framework-oriented and statute-oriented agreements. The former "are dominated by constitutive rules that specify basic structure, institutional forms, procedures and rights," and "define modes of interaction without specifying when these modes must be employed or to what end." Statute-oriented agreements "are dominated by specific codes that regulate the behaviour of actors under specific circumstances," governing 
how and when certain actions should be taken or avoided (2002, p. 391). As with oversight mechanisms, the underlying assumption in operation is that where there is more leeway there is more trust, and frameworks provide a greater degree of latitude than statutes. Individual agreements will typically contain elements of both types, and require careful analysis to determine which type predominates. Nevertheless, Hoffman finds this distinction far more useful in the detection of trust than the mere presence or absence of written agreements, which have in themselves often been taken to indicate a lack of trust, despite their necessity for the functioning of modern states at all levels of organization (2002, pp. 392-393).

Hoffman recommends considering all three parameters when attempting to identify trusting relationships, and assumes that they should converge in the presence of trust. Where they do not, the first measure, that identifies policies granting discretion to others, especially where there is documentary evidence that these policies are motivated by trust, is given greater weight but tends to be more difficult to assess, as the necessary evidence may be difficult to obtain. The second and third measures rely on evidence more likely to be in the public domain, but are considered more "errorprone" than the first, presumably as a result of the greater need for interpretation by the analyst (Hoffman, 2002, p. 393). Having by these measures come to some determination regarding the degree of trust that characterizes a particular interstate relationship or instance of their cooperation, the question remains as to what use such insight might be put. If "at root, this is a theoretical project" (2002, p. 376), then it stands or falls on its success in enabling the identification of cooperation in a manner independent of trust, and if successful, might serve as a tool for unpicking the knot that binds these concepts for Kydd, opening the latter's analysis to the possibility that seemingly cooperative actions may be otherwise, or at least additionally, motivated than by the need to manifest trustworthiness.

As noted above, the fiduciary definition developed by Hoffman considers trust to be a special case of risk, qualified by the trustor's belief that the trustee is obliged in some degree to honour that trust, despite the fact that "the expectations of trustors do not automatically bind their trustees to a particular course of action.... Trustors create trusting relationships; trustees determine the success of these relationships" (Hoffman, 2002, p. 381). The relinquishing of a measure of control over certain of one's interests to another, in the expectation that these or some other interests will benefit, is 
a bet laid by the trustor on the likelihood that the trustee will meet its "obligations," that it will, in short, cooperate. The first arm of Kydd's definition simply rephrases this formulation: trust is the expectation of cooperation. But Hoffman does not complete the circle; cooperation here is not necessarily the behavioural manifestation of sufficient trust, as it is for Kydd. US-Soviet nuclear cooperation certainly involved each placing interests at risk of harm by the actions of the other, but the cooperation of each in this was not "based on a belief that the other had an obligation to avoid taking advantage of them." The risk-taking cooperative behaviour of each therefore falls outside the narrower category of trust.

This assertion of the possibility of trust-free cooperation is made as if stating the merely obvious, an assertion bolstered by the use of the most obvious example of all, the only example provided and, Hoffman must assume, the only one needed to counter the essentially inductive claim that cooperation is possible only on the basis of trust. But once again, the employment as example of such a singular case should give us pause. The quality most clearly exemplified by the US-Soviet relationship is its very uniqueness, and in attempting to make it stand as the most representative member of a class of interstate relationships, Hoffman risks casting it as the exception by which the rule that predicates cooperation on trust is proved. And to underscore the point, the defining and so far unreplicated aspect of this unique relationship, "the threat of mutual destruction," replaces trust as the sufficient cause for their cooperation, as if this alone could explain that between any other pairing (Hoffman, 2002, p. 381). It may be, then, that there is insufficient here to prevent Kydd's noose from tightening around Hoffman's analysis, again reducing cooperation to a matter of trust, despite his best intentions.

Even if this is the case, and we could find no other instance of cooperation that was not founded on trust, it may still be that Hoffman's indicators are of some operational value, as he would have it, in discerning the level of trust that underlies any particular occurrence. If we return to Kydd's example of Soviet self-dismemberment, in which he perceives the overturning of the history of rapidly diminishing trust of a security-seeking US in an untrustworthy, because expansionist, USSR that characterized the Cold War period (Kydd, 2005, pp. 115-116), it is clear that Hoffman's measures are as overwhelmed by the narrative of abnegation bordering on the pathetic according to which the Soviet Union is given to have demonstrated its trustworthiness 
as is Kydd's analysis. To describe this event as the result of a granting of discretion over interests and a certain leeway in the monitoring of its exercise, whether or not Gorbachev recorded his feelings of trust for Reagan and Bush, seems hopelessly inadequate, or at best comically understated. This is once again a problem of example, but not one merely of having chosen the wrong case to illustrate the point; and to be fair, on this point it is not the example Hoffman uses. Those he does choose - the preWorld War I arrangement between Germany and Austria-Hungary, the US food aid programme, the relinquishing of veto powers in favour of qualified majority voting by European Community states in their dealings with one another, the US constitutional convention, and others (Hoffman, 2002, pp. 385-387) - provide for nuanced calculations of degrees of trust by careful examination of extant evidence that could perhaps, at least in principle, be used to draw conclusions regarding the forms or extent of cooperation that might be expected between particular states, or between states in particular kinds of relationship to one another, as defined by the metric of trust as a "continuous variable" (2002, p. 387). We might therefore be tempted to see Kydd's USSoviet example as a kind of limiting case in which the level of trust has been turned up to such a degree that the most vital interests, those critical to the integrity of the state itself, are risked by placing them squarely in the hands of another, as if in a gesture of sacrificial obeisance. Aside from the sheer historical implausibility of this story, such an act, in so exceeding the limits of trust, must also exceed the limits of cooperation by demanding, in effect, defection from the trustee. Cooperation in accepting a sacrifice of this magnitude amounts to "winning" the game by destruction of the opponent, a defection by any standard.

\section{Exchange relationships: equilibrium and asymmetry}

The divided example of US-Soviet cooperation at the height of the Cold War and at its end, in its respective appearances at the limits of distrust and trust, represents, precisely in virtue of its singularity and unrepeatability, the "culminating point" of the game-theoretical model of interstate relations. And this point occurs, ironically enough, at the moment the model encounters the realm of the purely strategic. In contrast with this strategic realm, we might posit another, in which more nearly linear relationships between trust and cooperation, values and perceptions, action and re- 
sponse pertain, and where the pressures of conflict do not trigger the abrupt reversals and apparent paradoxes that are endemic to strategy. The logic in operation here could be described as economic, or more broadly, as one of exchange. It is towards this realm that interstate relations move as they are said to "normalize," typically after having been characterized by more strategic interactions. Examples that approach being purely exchange relations are those between, say, New Zealand and Australia, or the US and Canada. Cooperation here is clearly the norm, and any specific case would conform closely with Hoffman's measures that indicate high levels of trust underlying and facilitating them, as his examples demonstrate. Limited disputes and disagreements may and do occur, of course, perhaps related to trade tariffs, or to the continuity and routes of pipeline and transport mechanisms across land borders, to cite two possible instances, but the shadow of the future looms large over the conduct of any such dispute, the interests at stake will generally be peripheral, and the values engaged in their pursuit will be congruent and mutually reinforcing in respect of the pressure applied in their name. Interests of greater importance, particularly those considered vital to the integrity of the state, are likely to be held in common with those in which one is in a relationship of exchange, commensurate with the similarities of value that motivate the state's actions and understandings. Where there are differences, there will be clearly established channels of communication and procedural rules governing their use, enabling any necessary negotiations and reducing substantially the risk of misinterpretation and misdeed.

The notion of exchange that is taken to define these relationships is drawn from the sociological theories of such authors as George Homans, John Thibaut and Harold Kelley, and Peter Blau. In one of the founding statements of what came to be known as social exchange theory, Homans wishes to revive, or perhaps to rehabilitate for the purposes of the study of social psychology "one of the oldest theories of social behavior," that amounts to a kind of folk psychology, "the view that interaction between persons is an exchange of goods, material and non-material" (Homans, 1958, p. 597). The "paradigm of elementary social behavior" consists in the behaviours of two entities, that of each reinforced by that of the other. In choosing among the different courses of behaviour open to it, each actor may acquire values which reinforce the behaviour, or incur costs that tend to mitigate it. Thus, "the problem of the elementary sociologist is to state propositions relating the variations in the values and costs of 
each man to his frequency distribution of behavior among alternatives, where the values (in the mathematical sense) taken by these variable [sic] for one man determine in part their values for the other" (1958, pp. 598-599). Homans observes that these behaviours and the interdependent values that reinforce them "often appear to be in practical equilibrium" in the case of small groups studied in the field. He means no more by this than "that for the time we are with a group - and it is often short - there is no great change in the values of the variables we choose to measure" $(1958, \mathrm{p}$. 600). As mere observed regularity, it explains nothing, and cannot be assumed, but on the contrary demands explanation when it is seen. To this end, he invokes what amounts to the corollary of his primary folk-psychological theory: "Mankind has always assumed that a person stabilizes his behavior, at least in the short run, at the point where he is doing the best he can for himself under the circumstances, though his best may not be a 'rational' best, and what he can do may not be at all easy to specify, except that he is not apt to think like one of the theoretical antagonists in the Theory of Games" (1958, p. 601). Despite the well-aimed slight directed at von Neumann and Morgenstern, Homans has summarized the essential conundrum that for these authors confronts the "participant in a social exchange economy," who in trying "to obtain an optimum result ... must enter into relations of exchange with others," in which "the result for each one will depend in general not merely upon his own actions but on those of others as well. Thus each participant attempts to maximize a function (his above-mentioned 'result') of which he does not control all variables" (von Neumann \& Morgenstern, 2004, pp. 10-11).

These formulations appear, on the face of it, to be entirely compatible. The distinction, which has become somewhat obscured in the work on international relations which nominally takes up the mantle of social exchange theory, ${ }^{3}$ is captured by Homans' barbed remark, and it makes all the difference. "To think like" a von Neumann-Morgenstern actor is to think like every other one; each may have a unique "function" and control its own fraction of the variables pertinent to the maximization of that function, but each will wield these in the same manner with respect to an opponent pursuing its own function. Equilibrium here, whether observed or not, is a

\footnotetext{
${ }^{3}$ Epitomized in the special edition of International Negotiation from 1998 devoted to the topic.
} 
state derived from the interplay of these functions and their variables, irrespective of any other attributes of the actor. For Homans, on the other hand, behavioural equilibrium is observed when the range of behaviours available to an actor on the basis of their consistency with the actor's motivating values is narrowed in response to those behaviours of another actor, which have themselves been chosen from a range motivated by values and narrowed down by the actions of the others. "Reinforcement" does not imply that the other's behaviour is viewed positively or as an instance of cooperation, merely that it can elicit a response motivated without significant contradiction by the actor's value system, and where these behaviours have come into equilibrium, continue to do so for a time. There need therefore be no symmetry between the actors' values, and they need not "think alike" in order to exchange behaviours, or even to maintain an "economy" of such exchanges.

Homans' insistence on the specific "circumstances" of his actor enables him to avoid the criticism that Schelling levels at von Neumann and Morgenstern who, as a result of their assumption of symmetry between actors, fail to distinguish between the communicative functions of "talk" and "action" (Schelling, 1980, pp. 116-117). Where such symmetry occurs, or is imagined to occur, and the values of one actor map (or are imagined to map) onto those of the other, then the utterances of one can be interpreted by the other as if by its own lights. But where no such correspondence of values pertains, which is to say in at least almost every real exchange, mere utterances are always suspect. In other words, an utterance, like any other action, will be interpreted on the basis of what it does rather than what it means. Statements of intention or reassurance, for instance, when passed between the like-minded, might in certain situations be taken at face value by both parties, and in these cases, the performative and constative functions of language may overlap to a considerable degree. Interlocutors with interpretive frameworks so closely aligned are likely rare enough, but even more rarely will they find themselves sharing circumstances so propitious as to warrant such faith. The moment we depart from these conditions, such statements become utterly unreliable. Potential interpretations multiply as value systems drift apart, perhaps until these values become so fixed in opposition at the other extreme that a statement's meaning will again come to rest, only now in its antithesis. Certain utterances may nevertheless do some work, but will do so in their capacity as actions in themselves: that a statement is made by a particular actor in a particular context 
may be far more likely than its content to trigger a reciprocal action in response. Actions of other kinds, conversely, may come to bear a significance out of proportion with their material effects. If "talk is cheap," it is because the assumption of the transparency of talk is premised on the symmetry between the values and attendant interpretive systems of interlocutors, and were such symmetry ever to be observed, in those instances there would be little value in exchange. The communicative function of action (including acts of communication), on the other hand, is an acknowledgement that exchange can occur only where there is asymmetry. The signal must cost if it is to figure in an exchange, and all the more if the value acquired is of a different kind than that expended. The action becomes a signal through the exploitation of asymmetry within and between value systems, gathering to itself both meaning and uncertainty in varying degrees, and is the means by which each actor can "communicate his value system with some truth, although each can also gain by deceiving. While one's maneuvers are not unambiguous in their revelation of one's value systems and may even be deliberately deceptive, they nevertheless have an evidential quality that mere speech does not" (Schelling, 1980, p. 117).

\section{Reciprocity and strategy}

The limits of the exchange relationship, then, are defined by the degree of symmetry between the values of the actors involved. Where there is perfect symmetry, there remains nothing to be exchanged, and where there is absolute dissymmetry and no point of contact between values, exchange is perverse. Schelling's interactants exchange behaviours motivated by the furtherance of their respective interests in the service of values, sometimes revealing, sometimes obscuring aspects and elements of those values as circumstances and the other's behaviour demands. These mutually reinforcing behaviours will be observed to find periods of equilibrium, which may work either to stabilize value systems both internally and with respect to one another, or to cause one or both systems to shift somewhat, motivating new revealing and obscuring behaviours which will in turn reach a new equilibrium.

Joseph Lepgold and George Shambaugh have elaborated a typology of "reciprocal exchange" relationships in the context of international relations that groups these equilibria into four broad patterns, distinguished according to the expectations held by 
each party to the relationship with respect to two criteria.

Equivalence indicates how closely in value the items to be traded will be matched. It ranges from highly precise to very imprecise. Contingency concerns the extent to which one party's willingness to make a concession depends on a particular prior concession or favor from the other party. It ranges from high - a situation in which concessions are matched one for one to low - a situation in which one's willingness to make a concession does not depend on any particular action by the other party (Lepgold \& Shambaugh, 1998, p. 229).

When actors are confident regarding the reliability of beneficial exchanges, expectations that any particular exchange need be value-equivalent are reduced. Similarly, if the "time horizons" for each actor are sufficiently lengthy, expectations are lessened regarding the need for immediate reciprocation. There are in turn four dimensions that together comprise these time horizons: the life-cycle of the particular issue at hand; the shadow of the future linking two or more particular actors; assumptions regarding the other's ability to respond quickly; and an actor's own impatience the latter pair of dimensions being typically driven by domestic constraints, such as election cycles and bureaucracies (Lepgold \& Shambaugh, 1998, p. 230).

Expectations of equivalence and contingency constitute a pair of axes, as it were, against which can be plotted any given relationship of reciprocal exchange. Relationships in which the values of these variables converge, towards being both high or both low, are of the "polar" types identified by previous scholars as characterized by "specific" (high expectations) or "diffuse" (low expectations) reciprocity (Lepgold \& Shambaugh, 1998, pp. 231-235). To these are added a further pair of "mixed"-type patterns in which these variables are divergent: a pattern characterized by high expectations of equivalence coupled with low expectations of contingency, and a mirror-image pattern (1998, pp. 235-236). Each of these four patterns represents a mode of potential cooperation between states, and each implies on this basis a description of actions that would constitute defection and the available levers that states can apply in bargaining situations. States that approach each other with similar expectations of equivalence and contingency with respect to one another will each tend to find the 
other's behaviour reinforcing of its own in the course of their interactions. This is true not only of cooperative behaviour, but also of defections where these can be fairly readily interpreted and responded to from within the framework of these expectations. The scope for such interpretation of and response to defection increases as expectations that the other will adhere to rigid timelines and value-equivalence in their exchanges are relaxed in relationships of mixed-pattern and diffuse as compared with specific reciprocity. As a result, an equilibrium is likely to emerge, playing out as long as mutual expectations continue to be met, both in their confirmation and in their breach, at least up to a point.

A state of equilibrium will persist as long as the expectations of the actors involved remain stable and congruent, which is to say, as Lepgold and Shambaugh would have it, the "actors believe that they are in the same strategic situation" (1998, p. 237). Ongoing cooperation within the parameters established by these expectations, even if occasionally marred by easily assimilable defections, may encourage the participants to relax their expectations with respect to either or both criteria, and if these remain congruent, allow a new equilibrium to appear at a stage further along the implied normative hierarchy of exchange relationships, from specific to diffuse reciprocity. This movement is explicitly linked to a concomitant increase in the level of trust between actors, from the "fragile" cooperation between "mistrustful" actors who demand the immediate return of equivalent values $(1998$, p. 231$)$, to the more robust cooperation between actors willing to countenance the emergence of "unbalanced accounts" of acts that have gone unrequited and that may in less well-developed relationships have been considered unforgivable defections, but that can now on the contrary "build trust" in a sort of virtuous cycle that serves to "move [the parties] further toward the diffuse reciprocity polar type" (1998, p. 230).

An interstate relationship that has "evolved" into one of diffuse reciprocity across all or most domains of their interaction would therefore correspond with what was described above as a relationship of (near) "pure exchange," characterized by cooperation underpinned by a high degree of trust à la Hoffman. Once achieved, this equilibrium might be expected to be fairly stable, the expectations upon which it is built being relatively flexible and forgiving of minor transgressions. Other equilibria, characterized by less flexible styles of cooperation and correspondingly lower degrees of fiduciary trust, are likely, according to this model, to be more easily disrupted by de- 
fections of sufficient gravity, especially those which indicate that the strategic situation of at least one of the actors has changed. When such a change occurs with respect to a particular issue, cooperation ceases, and "strategy" consists in the application of "leverage" in an effort to establish a new equilibrium in keeping with the state's new expectations. For Lepgold and Shambaugh, this leverage takes two basic forms: the communication of a willingness to cooperate (now or in the future depending on the pattern of reciprocity at stake), or linkage of the issue at hand to another of value to the opposite party (1998, p. 238).

Thus, for these authors, in the extent to which the "strategic situations" of states overlap, there is no strategy, and their relations are governed by the logic of exchange. The particularities of this logic vary according to the expectations engendered by that situation, but because they are shared, the logic is linear: trust and cooperation are directly proportionate, and the specific circumstances of each state determine only the materials of exchange, their value and meaning being functions of the equilibrium itself. Where these strategic situations, as defined by the expectations states have with respect to the conditions of reciprocal exchange, do not conform with one another, trust and cooperation are suspended. If these states continue nevertheless to interact, whether by choice or necessity, their interactions become strategic. On the account presented in this thesis, the transition to strategy is to the non-linear, to the overturning of values in the very attempt to reinforce them, and to the thwarting of intentions precisely to the extent that they are actively pursued: in short, it is to enter a realm in which the logic of exchange can find no purchase. The levers offered by Lepgold and Shambaugh, on the other hand, are an attempt to apply the tools of exchange to the problems of strategy, to cast the strategic moment as at best a special case, or at worst as an interruption, of the properly "economic" functioning of interstate relations, to be tackled by lifting it back onto the rails of reciprocity guided by parallel expectations. As these authors confess, "[w]e have left almost entirely unexplored the bargaining and signaling processes by which reciprocal relations form and are transformed" (1998, p. 250), but they have gone so far as to assume that the logic governing processes occurring within these relations must also pertain without. Disequilibrium for them, as for von Neumann and Morgenstern, is merely a state of play in which the "functions" of the players have not (yet) been "maximized" - reciprocity is still the only game in town, and strategy is reduced to the means by which opponents come to 
some sort of agreement on the questions of who owes what and when it is to be paid.

This iteration of social exchange theory, in drawing rather heavily on the gametheoretical apparatus, is similarly confronted with an impasse in its attempt to grapple with the strategic implications of cooperation. For the game-theoretical account, as we have seen, retaining the intuition that cooperation and trust are indissolubly linked comes at the risk of courting absurdity as competing values move ever further into opposition, raising as they go the costs of defection, and so tempting, by its own logic of backwards induction, the conclusion that the intuition might have been absurd all along. And yet the link resists analysis, so obvious and overwhelming is the counterexample (that continues to cast a shadow over our understanding of the current epoch even when such understanding is disavowed as "Cold War thinking") that it appears to induce a strange reversal of induction: trust so clearly does not function to sustain cooperation in this single instance that it simply must do so everywhere else.

This much is taken for granted in Lepgold and Shambaugh's theory of reciprocity - as cooperation in the form of reciprocity evolves, so too trust. Here, the problem of cooperation hangs on the possibility of equilibrium derived from symmetries of expectations and values between actors. As a result, cooperation is a more nuanced concept than it typically is for game theory, no longer an "either/or" proposition, but admitting of degrees. Cooperation (and trust) is limited where the expectations of each regarding certain behaviours of the other are rigorously upheld in the demand for highly symmetrical exchanges, implying a corresponding asymmetry between otherwise conflicting value systems. Conversely, deeper reciprocity is premised on a relaxation of the demand for symmetrical exchange of specific values, as value systems on the whole become more aligned. Nevertheless, at all stages of the evolving relationship, in order for cooperation to occur, the theory demands that each actor must expect the other to behave as it does itself in respect of their exchanges; demands, in effect, that each is playing the same game. Social exchange theory so conceived is static, able to describe the structures of equilibria and the behaviours of actors as functions within them, but leaving "almost entirely unexplored" the discontinuities that separate one such state of equilibrium from another, except to posit that these transitions must be little more than deferments of the game, to be taken up again at a later time and/or with different objects of exchange (albeit "linked" to the objects of previous exchanges) and perhaps a slight modification of the rules. 


\section{Strategic equilibrium: values and interests redux}

To the extent that it is reduced to these static structures, the theory of social exchange has departed in its essentials from Homans' early formulation, reversing the hierarchy between the propositional content of statements relating the values and behaviours of an actor with respect to those of another, and the theoretical structure that formalizes those statements. Thus, Lepgold and Shambaugh derive their theory of reciprocity from certain observations made by others regarding its limiting cases, then extrapolate from these to complete their typology. Only then do they undertake to plot the history of Chinese-American relations along the line they have already drawn for it (1998, pp. 237-248). Acknowledging that this practice does not constitute "a test in the strict sense," they claim nevertheless that their "interpretation of SinoAmericans [sic] relations through this lens confirms the analytic utility of our argument" (1998, p. 249), thereby begging the question. By carefully privileging what is there to be observed, structured only by the barest of theoretical premises, Homans seeks to avoid not only the circularity of this argument, but also the need to assume any symmetry between the values and expectations of those engaged in exchange. Equilibrium, when found, is a contingency arising from the specific circumstances and behaviours of those so engaged, not their determinant, and no particular implication regarding interactants' beliefs and motivations can be drawn solely from observing a period of apparent behavioural stability in a given relationship.

Schelling's insistence on the primacy of action over talk may be seen to be similarly underwritten by a suspicion regarding the circularity of totalizing theories and their homogenizing tendencies. In the reading of Schelling given above (pp. 37-38), the meaning of an action, or of an exchange of actions, is determined by the asymmetry and discontinuities between value systems, even where there is substantial overlap. Thus, the identification of a series of exchanges as a cooperative equilibrium cannot be taken as evidence of the supposed convergence of expectations said to have given rise to the equilibrium, as there is no vantage from which to usefully make such an identification that lies outside the interpretive systems of the actors involved. Cooperation, or defection, is in the eye of the beholder, and the asymmetries that make a communicative action possible also introduce the possibility of misinterpretation and deception. Shared understandings occur, of course, and may even be the norm in 
many interstate relationships, but in order to function as such, their mutuality must itself be communicated and will therefore be subject to similar vagaries.

When behavioural exchange is viewed from this perspective, strategy becomes intrinsic to its functioning rather than what occurs when exchange breaks down or transitions from one equilibrium to the next, and cooperation becomes the special case of a more general category of conflict. To reiterate: value systems motivate, give meaning to and adjust to the actions that are their material expression, giving rise to their specific and situated histories. Very few such systems develop in isolation, most will come into contact with others early in their histories, and some, at least, will have their origins in conflict. All action, therefore, is already interaction, directly or by implication, and can be considered in terms of exchange underwritten by asymmetrical values. As discussed earlier ("Values and interests," pp. 23-26), any action undertaken will be commensurate with some values, and will generally be in conflict with others within the same system. The continued pursuit of such an action will meet with ever greater resistance from within the system that generates it until a culminating point is reached when the initiating values themselves are at risk of being undermined. When this action is undertaken in respect of another value system, it will likewise be interpreted and responded to according to competing values within that system, whether this is considered on the whole to be in alignment or in conflict with the actor's system. The action or behaviour offered in exchange will, of course be subject to similar "internal" and "external" environments of competing values and culminating points.

Any action, therefore, may be considered strategically, even though most are not; an action in this sense is a disturbance occurring within a web of values that are in conflict with one another to a greater or lesser degree. Certain regions of this web, whether differentiated as a relatively discrete "system," a part of such a system, or a point of interaction between systems, will be relatively elastic, and actions motivated by specific values or clusters of values may be pursued at some length before meeting significant resistance. Most actions most of the time, whether on the part of individuals, organizations or states, will be of this kind, and will barely merit any kind of strategic scrutiny. But even these actions, if pursued for a sufficient duration, or in the face of a realignment, perhaps unnoticed, of competing values as a result of other actions, will meet their culminating points, and usually in ways that will come as a sur- 
prise to unsuspecting actors.

Other regions are rigid to the point of fragility, and almost any action will be blocked from the outset by incommensurate values; any forceful pursuit of such actions risks shattering the very values that underlie them by exposing those values to contradiction and nonsense. Strategy here is either a non-starter or self-defeating, except insofar as this feature might be exploited by a strategic action motivated by values from elsewhere in the "web," but co-opting a rigidly-bound value or set of values for the purpose of overturning it, as was argued above with respect to the fall of the Soviet Union (pp. 26-27).

Yet other regions of the network of values fall, it will be surmised, somewhere between these extremes in terms of relative rigidity, and are therefore susceptible to strategic thinking regarding how to act in furtherance of certain values in the face of opposition. For a state at any given time, certain values are "operationalized" as interests, and the actions to which these give rise are typically explicitly strategic. Earlier, in the context of our discussion of interstate engagements as mixed-motive games (pp. 25-26), interests were described as particular valuations of the future and prospective payoffs, triggering actions characterized by cooperation with or defection from the complementary interests of an opponent. For interests to count as such, they must be at play within these contested regions, subject to various pressures but not crushed to the point beyond which they can incite no viable action. Interests may usefully be considered as values that have arisen from a contest within a given system, but are put to work in certain of the interactions between competing systems, primarily those involved in establishing and maintaining, or remaking, the boundaries between them. Interests are therefore reflexive - generated at one level by the distinction between the inside and the outside of a value system, between, so to speak, "us" and "them," their function is to make and remake the same basic distinction as circumstances demand. As far as possible, the aim is to preserve the system bounded by these interests, often by re-casting certain distinctions, if necessary, in the vein of Palmerston's quip regarding "eternal allies" and "perpetual enemies" versus "eternal and perpetual ... interests" (Palmerston, 1848). On occasion, the pressures brought to bear on a system may be such that certain interests must be sacrificed in a more fundamental rearrangement of values designed to accommodate the preservation of a distinction; so might be interpreted Britain's semi-voluntary, or at least more-or-less 
cheerful submission to the inevitable relinquishing of its major power status to America, completed between the World Wars in the name of a "special" Anglo-American relationship (Coker, 2015, pp. 85-87).

Interests function, then, at the interface between value systems; firstly to maintain the integrity of the system against external pressures, and secondly to extend it. This is not to be confused with territorial control or direct influence over others by the state, although actions that contribute to these outcomes will certainly be motivated by interests. As Britain's peaceful withdrawal in favour of the US demonstrates, an interest in the maintenance of sea lines and a more or less liberal global economic order was felt to be more vital to the integrity of British economic and political stability than was the interest in remaining the guarantor of that order against a rising US power which it could no longer hope to contain. This is superficially analogous to White's claim regarding the cooperative move by the US that would satisfy China's ideal, and illustrates Robert Keohane's assertion that "[c]ooperation involves mutual adjustment and can only arise from conflict or potential conflict. It must therefore be distinguished from harmony. Discord, which is the opposite of harmony, stimulates demand for policy adjustments, which can either lead to cooperation or to continued, perhaps intensified, discord" (Keohane, 2005, p. 63).

For value systems in complete harmony, no interests as such are at stake, and conflict and cooperation are moot, as actions undertaken in accordance with one set of values meet no resistance from the other. Total discord would render conflict and cooperation equally redundant, as any action on the part of one system must be immediately negated in the other. These theoretical limits to the relationships between value systems may be approached but not achieved, as Keohane implicitly recognizes. Discord, then, describes any departure from total harmony between states, a departure that opens up in its wake an asymmetrical space of interaction between systems, defined by interests and the potential for conflict and cooperation. "Policy adjustments" to these interests or to the manner in which they are pursued are made in response to the pressures exerted by opposing interests, either resisting or accommodating those pressures, and exerting or relaxing pressures of their own. Actions undertaken in this space, in accordance with the interests that define it, may exert pressure here but relieve it there, such that the distinction between cooperation and conflict becomes all too often a matter of interpretation, the formulation of which must itself be an inter- 
ested act. It remains the case, however, that any such action is taken in relation to the discordant interests of another, and one may therefore wish to go one step beyond Keohane, and assert that cooperation does not merely arise from conflict, but is, to borrow Clausewitz's phrasing, "simply a continuation" of conflict "with the addition of other means" (von Clausewitz, 1976, p. 605).

\section{Cooperation as conflict: narrative origins of trust and distrust}

If it is the case that state interaction can occur only in a field bounded by discordant interests, then it is conflictual as a matter of structural necessity, and its conduct is subject to the strategic logic of reversal elaborated above (especially p. 24). Interactions governed by this logic are by their very nature unstable, requiring constant attention and adjustment in order to avoid overextending actions that will thereby put their motivating interests at risk. That the pursuit of interests must engender the instability that undermines them may stand as the defining strategic conundrum of interstate relations, to which cooperation provides a partial and imperfect solution.

A cooperative act is one that signals itself as such. In the conflictual and asymmetrical space of state interaction, this signal must be costly, which is to say that it must involve the surrendering of some value, or at the very least must put some value at real risk of surrender. The acceptance of this signal is demonstrated by the telegraphing of reciprocal surrendering of a value, and so on. For as long as this contingent exchange of costly signals continues, we will observe a period of cooperative "equilibrium," but contra the game theory-inspired proponents of exchange theory, even apparently stable and prolonged reciprocity of this kind represents the aberrant form of interstate relations. Rather than seeing the history of these relations as one of periods of stable exchange punctuated by moments of discontinuity that occur in response to shifting expectations, we observe instead a background of structural instability and necessary conflict that may at times (even for extended periods) be at least partially obscured by seemingly stable cooperation.

The immediate purpose of interstate cooperation, when considered as a sort of mutated form of conflict, is simply to delay what nevertheless remains the inevitable culminating point of a given course of action. The mutual acceptance and reciprocation of costly signals serves to relieve to some extent the pressure of opposition to cer- 
tain actions and the interests that underwrite them, allowing their relatively unimpeded continuation and reinforcement for a time. But such an exchange must involve prioritization and compromise, and therefore cannot continue indefinitely. If the value sacrificed to the interest in question is too high, it will inspire internal dissent and demands for its restoration; too low, and the opposing power will not long accept its currency. Neither can a "perfect" balance be for ever sustained in a dynamic system of intersecting values subject to the constant buffeting of action and reaction occurring within and from all sides. Thus will even the most mutually beneficial of cooperative exchanges ultimately falter, perhaps to be replaced by another if not too great a rearrangement of values has taken place in the meantime, but at least as likely to reveal the undercurrents of conflict that continue to drive the relationship.

Nevertheless, between certain states may be observed prolonged periods of cooperation across multiple fronts - economic, military and cultural, for example (and it is to be hoped that environmental cooperation may meaningfully be added to this list before too long). The various dimensions of such multifaceted cooperation appear to be mutually stabilizing and sustaining, in part by allowing the costs of cooperative signals, as well as those of minor transgressions, to be spread across a greater range of values with a correspondingly greater capacity to absorb the pressures of internal dissent and external opposition, and so further delaying the culminating point of cooperative action. Over time, the conflictual origins of any given interstate relationship may all but disappear beneath a thick veneer of cooperation, which comes increasingly to be viewed as itself fundamental to their interactions, with its own distinct mode and measure: trust.

As we have seen, attempts to account for the apparently constitutive link between trust and cooperation seem doomed to circularity, even when the intention is to decouple the pair and consider them as independent variables. However, if this perplexing layer of long-term cooperation can be peeled back to reveal the substrate of conflict between competing interests, the knot unties itself. Cooperation is merely one strategic response, albeit one with certain desirable side-effects, to the structurally necessary conflict in which all interacting states are engaged. Trust then becomes a narrative representation of cooperation, and a sort of surplus value generated by cooperative exchange that may be reinvested by way of justifying the future expenditure of value in ongoing cooperation and the resulting stability that in turn tends to protect in- 
terests. Likewise, "breaches" of trust may provide narrative justification for making alternative strategic choices, but are not themselves the cause of conflict.

The perfect circle of trust and cooperation captured by Kydd can be prised open when we see trust operating both as a value generated by cooperation and as a narrative of the origins of cooperation, as a function both of the "real" and of the "imaginary." Trust is a real effect of cooperation insofar as it consists in the materially effective beliefs and expectations of actors, as described by Kydd, Hoffman and others, and from which in turn are generated the retrospective narratives of trustworthiness, shared history and common values that provide the well-manured topsoil in which the germinating seeds of cooperation are imagined to lie, innocent of the rocky and uncertain terrain in which they must actually take root.

The conflation of what I am loosely designating the "real" and "imaginary" aspects of trust underlies the confusion regarding the direction of causality in the relationship between trust and cooperation. The imaginary origins of cooperation in trust between states (or their leaders) obscure its real origins in conflict, and this story has become sufficiently compelling that considerable efforts and resources, not to mention ink, are devoted to "trust building" as a means of fostering cooperation. While such efforts need not in themselves hinder cooperation except insofar as they are a distraction, and the narratives produced may conceivably enhance strategies of cooperation already underway, the unfortunate corollary of this tale is that distrust must therefore be the primary impediment to cooperation between adversaries. This is the central claim made by Kenneth Lieberthal and Wang Jisi in their influential monograph on Addressing U.S.-China Strategic Distrust (2012).

Lieberthal and Wang coin the term "strategic distrust," which "means a perception that the other side will seek to achieve its key long term goals at concerted cost to your own side's core prospects and interests ... and that this perception can, if it festers, create a self-fulfilling prophecy of overall mutual antagonism" (Lieberthal \& Wang, 2012, p. 5). Their paper is replete with examples of distrustful perceptions of the other held by respective Chinese and American political, military and diplomatic elites, which appear to involve every aspect of their relationship, and which for each seem subject only to reinforcement by the talk and actions of the other. Wang claims that Beijing sees "that China-U.S. cooperation must be based on mutual strategic trust," but that "it is U.S. policies, attitude, and misperception that cause the lack of 
mutual trust between the two countries" (2012, p. 7). From the outset of his elaboration of the U.S. position, Lieberthal is adamant that "[s]trategic distrust of China is not the current dominant view of national decision makers in the U.S. government," which "rather sees the prospect for both Beijing and Washington to adopt policies that lead to the type of long-term relationship that one expects to characterize ties between two basically cooperative major powers" (2012, p. 20). Nevertheless, China's "very undetermined" (2012, p. 21) future gives pause to American optimism regarding the relationship, and Lieberthal proceeds, in spite of his opening protestations, to expatiate on the depth and breadth of American distrust of China on basis of this uncertainty, which permeates their interactions across the realms of politics, diplomacy, economics, intelligence and military matters (2012, pp. 22-33).

Following these individual forays into the attitudes of their respective nations, the authors come back together to lament this sorry state of affairs and to offer some suggestions towards beginning the "vitally necessary" work of "building strategic trust" (Lieberthal \& Wang, 2012, p. 39). ${ }^{4}$ They strike a similar note in their opening contribution to Debating China (Hachigian, 2014), a collection of epistolary dialogues between Chinese and American experts on various aspects of the relationship, and this tone reverberates throughout the debates in which each author first bemoans the distrust that must surely hamper cooperation, tends after a balanced assessment to hold the other side somewhat more responsible for this than their own, and then marvels at the substantial (if always insufficient) cooperation in evidence across each layer of US-China interaction. One writer, Yuan Peng, ends his first missive with a gesture towards the possibility that conventional wisdom regarding trust and cooperation might be reversed: "mutual trust can only be established gradually after a period of sustained cooperation" (2014, p. 94). However, in Yuan's next letter, the old narrative reasserts itself in his restatement of the apparent conundrum in which all these authors remain bogged: "What can we do to improve our effective and meaningful cooperation? I

\footnotetext{
${ }^{4}$ This project is given full voice in the extravagantly titled 2014 report on Building U.S.-China Trust Through Next Generation People, Platforms \& Programs, commissioned by the U.S.China Bi-National Commission on Trust-Building and Enhancing Relations, co-chaired by Wang Jisi. The work of this body is founded on the assertion that "[t]rust is essential for the two nations to work collaboratively to address shared challenges," and that "[d]eliberate and sustained efforts at trust-building will enhance the capacity of the two nations to cooperate more fully and manage differences more effectively" (2014).
} 
think mutual trust is the key" (2014, p. 103). The force exerted by the notion of trust as the imagined necessary progenitor of cooperation is such that it seems to override the extensive evidence of cooperation between these powers that is cited, and even materially contributed to, by many of these authors. Furthermore, none finds it necessary to explore the means by which trust is supposed to generate cooperation, and for each, Yuan's brief excursion towards a contrary view notwithstanding, that it simply does stands as an unexamined assumption.

If these authors have between them not only correctly identified true instances of cooperation, but have also correctly diagnosed the malaise of strategic distrust that characterizes the China-US relationship, then their primary assumption concerning the dependence of cooperation on trust cannot be the case. Nevertheless, the coincidence of cooperation and strategic distrust may be no more than just that, and while it may be argued on the grounds of this coincidence that trust cannot be a necessary condition for cooperation, it does not on its own justify the further claim that trust may not be sufficient to engender cooperation. A stronger definition of the supposed link between the two, such as that provided by Kydd, does provide the opening for such an argument, as I hope to have shown earlier ("Strategic relationships 2" pp. 29-34), but the weakness of Lieberthal and Wang's assumption allows us to glimpse a tantalizing possibility.

Trust and mistrust, for Kydd, represent no more than the diametrically opposed beliefs one may hold regarding the preferences held by the other with respect to cooperation and defection (see p. 29 above). This definition by simple opposition is strong, in that it admits of no exceptions, but brittle, when exposed to the contradictions it must entail. Lieberthal and Wang's definition of strategic distrust seems on its face to entail a similarly zero-sum interpretation of the long-term confrontation between those on either side of a distrusting relationship. However, while conflict, in the form of "mutual antagonism," may be the all but inevitable, if by no means the ultimate outcome of strategic distrust, cooperation is not thereby automatically excluded, as it is from the terms of Kydd's balanced equation of trust with cooperation, distrust with defection. This does not result only from the difference between Kydd's highly technical game theory and the discursive, not to say conversational approach taken by Lieberthal and Wang, as well as by Hachigian's other contributors, which allows for a rather greater degree of syntactical flexibility. Here again, there is also, 
and more importantly, their contrasting use of examples.

\section{Exemplary distrust: real and imaginary}

Kydd's examples are the analytic objects of his theory, dissected after a fashion that leaves him blind to what remains once he has extracted what he takes to be their core: the realization of his model. For the others, examples of cooperation and conflict proliferate in an unruly tangle, some in conformity with their thesis, others in direct contradiction, still others seem to be undecidable on this count - what else to make of the discussion of the Chinese currency exchange rate mechanism (Hachigian, 2014, pp. 25-31, 37-40)? No unified theory could hope to contain such profusion, and Lieberthal and Wang, et al. do not proffer one. Their formulation of strategic distrust is at best a rule of thumb in favour of which no example could stand as proof, and against which counter-example provides no argument. Examples of cooperation between China and the US abound, but they are never enough to furnish evidence of trust; examples of dispute and disagreement are to be found in every direction, but should not discourage us in our efforts at building trust. Such examples are not, in the end, examples of anything, they are merely observed contingencies, moments of equilibrium à la Homans, in which one actor has found its behaviour, however briefly, to be reinforced by that of the other. In short, examples are not to be trusted.

Yet there they are, and we seem to be powerless to resist the temptation to draw these examples into any number of narratives, stories that become theories driving predictions; these may be mutually incompatible, but they are able nevertheless to call upon even the very same examples as supporting evidence. Any such enterprise that eschewed examples altogether, however, would be treated with suspicion as groundless and ephemeral, and rightly so.

Examples must therefore be engaged, but they must be handled in a spirit of positive distrust. Kydd trusts his example implicitly, and is betrayed by it; the sheer profligacy evident in the raising of examples in Debating China mitigates against this kind of trust, but engenders only bewilderment in its place, leaving its authors little choice but to fall back onto old and familiar tropes, even if this means reversing any insights glimpsed while wading through the morass. In each case, there is a failure to find the example interesting in its own right, a failure to see, in effect, the conflict of 
interests in every example. In the first case, the example is merely illustrative, of interest only insofar as it is an expression of the model that gives it its structure; in the second, no example is so subordinated, and each can float free of any theoretical encumbrance by which it might be caught and pressed into the service of understanding. Which is to say that in neither instance is it the case that examples are put to any real work, being either too tightly shackled or on too loose a rein; they are just talk, whether highly formalised but otherwise empty pronouncements on the one hand, or idle chatter on the other. If it is to be taken seriously, an example must be given the force of an action, and must be confronted as one, with an attitude of distrust.

As Lieberthal and Wang suggest, this attitude pitches us in a necessarily conflictual relationship with the example at hand. The "goal" of the example, so to speak, is to come to rest at either pole of its field of action, the points of maximum rigidity or maximum elasticity with respect to the theoretical question under scrutiny. At one extreme, the example simply mirrors the question, functioning as little more than a transparent restatement of the problem, and at the other it becomes opaque, having lost any specific connection to the issue. Whether perfectly congruent with or exactly orthogonal to the line of enquiry, in neither instance can the example further our understanding, but can at best serve only "rhetorical" ends. If it is to exert any force with respect to the question asked, the example cannot be allowed to fall too far towards either end of its trajectory, and must be kept aloft by a constant pressure of interrogation of the necessarily conflicting values that motivate it as action. The example, as action, is always interested, always has a stake in the question, and so can never simply be an answer. The moment it becomes merely an example-of and collapses into generality, or is similarly stripped of its specificity by dilution, motivation is lost and the example is now devoid of all interest. For argument by example to be fruitful, the tension between what we might call the "pure logic" of the question and the messy, value-laden and contradictory specificity of the example, or between what we might perhaps more simply call the imaginary and the real, must be maintained. Thus we might redefine strategic distrust (in contrast with a distrust that is the simple negation of trust), at least for these limited purposes, as the sense that the real will tend to collapse into the imaginary (and vice versa) unless we actively prevent it from doing so.

In operation, this distrust amounts, at first, to suspending the question in order to 
give the example full play. Thus we return to Hugh White's central question, which we may phrase: how should the US respond to China's rise? His answer, as we have seen, is ultimately unsatisfactory because it is too quick, too abstract; it imagines a coherent grand-strategic project where there are instead complex and disjointed but intersecting machineries of material and symbolic power operating in an equally complex and disjointed geopolitical context. The story told is of a future encompassed by a single decision taken in respect of a stark choice, but imagination fails in the moment that decision must become action, and the narrative founders on an example already too unwieldy to be constrained by so flimsy a device. White's only recourse is to double-down by inflating his example still further, from the barely manageable two-body problem of US-China relations to the gargantuan $n$-body problem of the Concert of Asia, and he contrives thereby to commit both types of error in his use of example.

The first error: White takes what he considers to be the real problem confronting the US and China, and casts it in a highly structured and idealized form that purports to exhaust the possible outcomes. The US-China relationship becomes no more than an example of the prisoners' dilemma, and present reality is all but doomed to imagined failure. The second error: as if in recognition of the first mistake, White embarks on his quest in search of the Concert of Asia, an avowed fantasy cut free from any of the constraints that bind the initial choice but that immediately runs aground on the shores of Asian geography and history and all that separates them from their European counterparts. The Concert of Asia is an example of nothing, a utopian figment that does not survive even momentary contact with the real.

White is bound to these errors by his insistence that his question can and should be answered on its own terms. But these terms, "respond" and "rise," not to mention "America" and "China," are functions of the imaginary, and an answer designed to balance their account, so to speak, will remain an abstraction. If instead, we hold them in abeyance, or perhaps as no more than signposts that direct our attention, in the most general way, we can otherwise ignore the fabricated limits these terms would impose. What we see, when we cast our gaze north, is not "Chinese rise" and "American response," but behaviour, (inter)actions driven by values and constrained by context. Scattered throughout this sea of behaviour, we may perceive practical equilibria, in Homans' sense, seemingly stable patterns of interaction in which, for a time, each 
actor's observable behaviour changes little and appears to elicit little change in that of the other. Many, if not most of these equilibria are of minimal strategic significance much, if not most of the time. The values brought to bear in these interactions may be shared or generally uncontested from outside the relevant system, and such exchanges may persist for long enough to acquire an air of durability that makes their eventual disruption all the more surprising, especially given that the shifts in values that spell their end are likely to be endemic to just one of the interacting systems, at least initially. The disruption or transformation of a stable exchange may, of course, trigger a shift in other systems as once subordinate values are called upon in the formulation of a response, perhaps strengthening their claims to priority and even to a reordering of the system. A ripple so started that strikes the interests that bound a given system with sufficient force may become intensely strategically significant.

\section{Distrusting narratives}

For example, consider the following plausible causal chain: the 2008 American banking crisis that generalised into a US and European financial crisis, and now into a more pervasive economic and political crisis, especially in Europe, has significantly reduced the size of the market into which China can export. At its peak in 2006, China exported $35.7 \%$ of its gross domestic product, and by 2015 , this had fallen to $22.4 \%$ (compared with its modern nadir of $2.5 \%$ in 1970). Over a similar period, China's GDP growth rate has fallen from a peak of $14.2 \%$ in 2007 to $6.9 \%$ in 2015 , and is projected to fall further through 2018 (World Bank, 2016). Domestic consumption is not rising quickly enough to offset the effect of declining exports on overall growth, which while seemingly healthy by world standards, is "fueled by debt-led investment" into inefficient state-owned enterprises (Magnier, 2016, April 15). Moreover, the fruits of this growth have been increasingly unevenly distributed within China and presage a potential employment crisis, especially in the country's interior (Chesters, 2016, pp. 5-6). President Xi's ongoing "reforms," focused in particular on "anti-corruption" measures, constitute an attempt simultaneously to curtail the economic inefficiencies of the state-owned enterprise system and consolidate authority over various powerful arms of the Party and military establishments in his own person, providing him with the means to maintain both economic growth and his chances 
of managing the social unrest that could result from failure, or even from success, should this lead to still greater inequality (Kroeber, 2013). Xi's efforts are ostensibly driven by his "China Dream" of a strong, civilized, harmonious and beautiful China to be achieved in two phases corresponding to two 100-year anniversaries: China is to be a "moderately well-off society" by around the time of the 100th anniversary of the Chinese Communist Party in 2020, and fully developed by the 100th anniversary of the People's Republic of China in 2049 (Kuhn, 2013, June 5).

Realization of Xi's dream, however, looks increasingly unlikely to occur, at least within the specified time frame. Whether this projected failure is considered by outside observers to be due to or in spite of Xi's success in drawing the Party and its organs of power into orbit around himself as the newly anointed “"core' leader" (Martina \& Lim, 2016, Oct 27), it is clear that his consolidation has gone hand in glove with a deepening nationalism, spurred by a sort of populism "with Chinese characteristics," to paraphrase an earlier "core" leader, Deng Xiaoping (1984). Yet it may well be that the further into the future the Dream recedes, the stronger the nationalistic fervour it inspires, and the greater the legitimacy Xi's centralizing project enjoys.

One of the primary effects of nationalism is to shift the range of values that are given the status of interests, and it achieves this in part by reversing the "normal" logical relationship between interests on the one hand, and threats and opportunities on the other. This logic, as drawn out in exhaustive detail by Terry Deibel, posits "the national interest" as rooted in those values that can be considered pertinent to the nation as a whole, and although subject in varying degrees to the subjective element "of where sovereignty is located within the state," can at least in principle be objectively determined, especially in democracies (Deibel, 2007, p. 136). Threats and opportunities are defined in relation to interests: "threats are only threats if they jeopardize an interest, and opportunities only opportunities if they can help the state advance an interest" (2007, p. 143). Nationalism, on the contrary, tends to generate narratives in which perceived threats and opportunities form the basis for newly- or re-defined interests, which not infrequently are derived from certain of the values specific to a particular segment of the nation in question. Against Deibel's liberal-democratic model, in which interests generated from within a national polity are projected outwards to meet external threats and opportunities on the international scene, a national-populist model internalizes threats (and to a lesser degree, opportunities) perceived as such 
from within an interpretive framework of avowedly exclusionary and besieged values. The purported existence of these threats reinforces the necessity and validity of the core nationalist values by which they are defined, and so gives rise to the basis of a foundational national narrative, in which the values opposed to the identified threats become vital, if not existential, interests.

The "China Dream" is such a narrative, telling the story of the rejuvenation of a specifically Han greatness, lost to the treachery and rapaciousness of the Western powers and Japan during the "century of humiliation," and to be restored only by the unifying power and clear vision of the Chinese Communist Party, which continues to defy those who would see its dream contained even now. As with all nationalist narratives, the China Dream is a construction primarily for domestic consumption, and in this context provides an enormously powerful justification for virtually any revisionist, or perhaps more correctly, revanchist foreign policy project the Party may entertain, as well as for its dominion over the various non-Han ethnicities within China's borders. Perhaps for the sake of consistency, it is also repackaged for export in the form of a quasi-historical rationale for China's adventures in the South and East China seas (Hayton, 2016, Sept 22). It seems reasonable to suppose that the Party does not expect those it sees arrayed against it to take its maritime claims seriously, and it is not important that they do so. Far more important is it that those manning the decks of its fishing fleets do; seriously enough, at any rate, to risk violent confrontation even with the coastguard and small naval ships of other nations in contested waters. Important too, the wave of popular dissent in response to the July 2016 ruling by the Arbitral Tribunal under the United Nations Convention on the Law of the Sea (UNCLOS) against Chinese claims, expressed particularly on various Chinese social media (Luo, 2016, July 19). Indeed, international opposition may even be welcomed for its salutary effect on national cohesion and support for Xi.

Managing the nationalist fervour it helps orchestrate is a delicate task for the Party, however. The legitimacy acquired by the regime in the course of pressing its claims may be lost if it is seen to compromise too readily, and there is a risk that it may be pushed from within into conflicts for which China is ill-prepared (Weiss, 2014, Nov 25). The only thing worse for the Party's image than backing down from a fight it provoked would be losing it, and there are several precedents in the Party's own history for the turning of popular support into dissent or even insurrection, from 
the Cultural Revolution and its aftermath to Tiananmen Square, twice (Kissinger, 2012, pp. 192-197, 318, 408-411). From this perspective, in brandishing the "doubleedged sword" of nationalism, the Party's strident declarations of strength are among the most telling signs of its weakness (Weiss, 2014, Nov 25).

Chinese behaviour in the South China Sea - island building, construction of military or "dual-use" installations, coastguard patrols and denial of access by other claimants even to parts of their own recognized exclusive economic zones - may be given to exemplify the expression of growing Chinese strength in the pursuit of something like its own Monroe Doctrine by attempting to establish hegemonic control over its near abroad. Equally plausibly, this behaviour may be seen to be driven primarily by mounting fears of domestic upheaval should the current spate of political, military and economic reforms fail adequately to address China's significant structural weaknesses. While it is the case that these explanatory narratives are by no means mutually exclusive, each calls upon a different, if overlapping, subset of interests in warranting its respective response from the US and its allies.

One response to this apparent quandary, as suggested by Merriden Varrall, is to refine our understanding of the Party's motivation by accounting for still further narrative underpinnings of its worldview, which is premised above all on the Party's being coterminous with the state itself. Varrall identifies four "key" narratives

used by Chinese leaders and elites to justify Chinese foreign policy actions and interpret the world: the century of humiliation; the view of cultural characteristics as being inherent and unchanging; the idea of history as destiny; and notions of filial piety and familial obligation as they apply both inside China and to China's neighbours (Varrall, 2015, p. 1).

Varrall goes on to show how each of these is deliberately invoked and manipulated by the "Party-state" (Varrall, 2015, p. 4) to varying degrees depending on the circumstances of the day, as explanation not only for China's actions, but also for those of its adversaries. Her analysis makes clear how pervasive these narratives are, from informing official Party declarations, to endless repetition in popular and social media, to providing the basis of historical education in schools. What is less clear is precisely how a nuanced appreciation of the Chinese worldview so described might 
inform the behaviour of the US and its allies in their interactions with China. Having established the malleability of the four narratives in their capacity to stand as justification for past failures (particularly the "century of humiliation"), present prejudices (unchanging cultural characteristics) and future aggressiveness ("history as destiny" and familial obligation), it remains for Varrall to demonstrate how "[t]he narratives can also help policymakers to understand what impact their responses to Chinese behaviour today will have on Chinese attitudes and behaviour in the future" (2015, p. 17). An understanding of how any such behaviours are likely to be represented by the Party and even by a large proportion of China's citizens is certainly to be gained, but the content of those behaviours will remain, on this account, entirely inscrutable.

Varrall does not raise the issue of trust explicitly, but her rendition of the four narratives might fairly stand as a rationalization for Chinese strategic distrust as described by Lieberthal and Wang, and is similarly unblushing in its capacity for the accommodation of proliferating examples and counter-examples. Perhaps in tacit recognition of the same risk of bewilderment that confronted our earlier considered letter-writers, Varrall admits, immediately following the last-quoted sentence, that “[u]ltimately, choices about how the United States and its allies respond to China need to be taken on a case-by-case basis" (2015, p. 17). This slightly lame appeal to an Anglo-American style of pragmatism in the conduct of interstate relations may be justifiable, but a considerable expanse of logical terrain is traversed by the silent paragraph break that sits between these two sentences. Mere understanding of the Chinese worldview, or at least of the narrative forms in which it is conventionally expressed, does not lead one seamlessly to a rational choice between one's own competing explanatory narratives, much less to a programme of action when presented with a given example of Chinese behaviour. Trusting that such understanding might so lead is to see behaviour subsumed by narrative, is to allow the substitution of talk for action.

The instantaneous and total collapse of the distinction between the real and imaginary that occurs here in the space of a paragraph break might be dismissed as a problem confined to academic attempts to navigate the troubled waters of US-China relations. Yet this tendency towards collapse is exploited by the parties themselves in the theatre of diplomacy, and its manipulation, conscious or otherwise, is key to the maintenance of cooperative equilibria. 


\section{Distrusting behaviours: real and imaginary}

On October 27, 2015, the US Navy conducted the first of its freedom of navigation operations (FONOP) directly in response to Chinese island-building projects atop various reefs and rocks in contested parts of the South China Sea. The guided-missile destroyer USS Lassen passed within 12 nautical miles of Subi Reef, one of seven Chinese-modified features in the Spratly Islands, within the claimed sovereign maritime regions not only of China, but also of Vietnam, the Philippines and Taiwan (Panda, 2015, Oct 28). This manoeuvre elicited an immediate official reaction from the Chinese Ministry of Foreign Affairs, as reflected in the comments by spokesperson Lu Kang at a press conference on the day of the operation.

Lu's remarks suggest the occurrence of a significant diplomatic breach, describing the American action as "completely different from transit passage and is nothing close to the so-called exercise of navigation freedom;" as illegal, threatening, dangerous and provocative; and as having "put the personnel and facilities on the islands and reefs at risk and endangered regional peace and stability." The assertion of China's "indisputable sovereignty over the Nansha [Spratly] Islands and their adjacent waters" is repeated several times by way of justifying the claim that its "sovereignty and security interests" had been trammelled. Failure of "the American side to take China's solemn representations seriously," and to continue "creating tension and stirring up troubles in the region" may cause "the Chinese side" to "reach the conclusion that we do need to step up and speed up relevant capacity building." Further, unspecified action could follow: "I would like to point out that the Chinese side is willing to remove differences through peaceful means, but when it has to react, it will decide when and how to react according to its will and its need." The question as to whether this might include "military actions" is pointedly evaded: "I have no comment on a hypothetical question" (Lu, 2015, Oct 27).

Considered in abstraction from the context of ongoing US-China interactions, Lu's comments strike a shrill, even bellicose tone, reverberant with sharp lines drawn in sand just waiting to be heaped on yet more reefs, and dark undercurrents of retaliatory action to come. They draw implicitly on various components of the China Dream narrative - past humiliations not to be repeated, historical claim as precedent, power no longer content to remain constrained - in magnifying the threat posed by the 
passing of a single ship approximately 1000 kilometres from coast of mainland China, to interests unspecified but nevertheless amplified in accordance with the calculus of nationalism. It is a statement with all the trappings of an ultimatum, but hints at responses sufficiently in excess of proportionality as to be stripped of meaningful content. The double-edged sword, so unsheathed, drew blood at home in the form of an outpouring of disdain on social media for the toothless scoldings of its Foreign Ministry (Allen-Ebrahimian \& Ryan, 2015, Oct 27), and has not prevented a further three such declared freedom of navigation operations undertaken by US naval vessels in the Spratly and Paracel Island groups over the succeeding twelve months. The possibility of Chinese action has been erased by rhetoric as the real disappears into the unquiet depths of the imaginary.

However, there is always a context, and where strategy is concerned, always an other for whom all action is interaction. The US has conducted freedom of navigation operations in the South China Sea and other Chinese maritime regional claims beyond its exclusive economic zone since 2011 (and throughout the world since 1979), although these had not before passed within the claimed 12 nautical mile territorial limit of any constructed islands (U.S. Department of Defense, 2015). That it intended now to do just that had been telegraphed in various media reports for some five months before the USS Lassen's voyage (Rapp-Hooper, 2015, Oct 12), and a statement released by Department of Defense officials to Foreign Policy declaring the operation's imminence was published in early October (De Luce \& McLeary, 2015, Oct 2). And in case any doubt remained, around eight hours before its passage past Subi reef, details regarding the Lassen's identity, its accompanying surveillance aircraft and its approximate location in the Spratlys were "leaked" to Reuters (Shalal \& Brunnstrom, 2015, Oct 26).

It may well prove that the US Navy's FONOP of 27 October, 2015 will stand as the least secret military operation of all time; as an action it could not, in any case, be faulted for lack of transparency. The action's meaning, however - legal, symbolic, strategic - has been the subject of debate that rivals medieval Talmudic scholarship for hermeneutic obscurity. Was the FONOP even a FONOP (Choi, 2015, Nov 3)? If it was, is that consistent with "innocent passage" (Graham, 2015, Nov 4)? If it was innocent passage, might this in fact have reinforced China's claim that Subi Reef should attract a territorial perimeter $(\mathrm{Ku}, 2015$, Nov 4)? Would it make a difference if 
it was both FONOP and innocent passage (Graham, 2015, Nov 9)? Might a challenge to China's territorial claims imply a broader challenge to claims of Chinese sovereignty in the South China Sea (Tiezzi, 2015, Sept 22)?

Underlying all of this (and there is much, much more of it) is a concern made explicit by many, but assumed by virtually all: "The Obama administration has not done a stellar job of explaining its actions at Subi Reef.... To ensure that China and other nations around the world fully understand what took place, the Pentagon should explain the legal basis for its operation and clarify what message it intended to send" (Glaser \& Dutton, 2015, Nov 6). To these authors, the voyage of the Lassen was a spectacle akin to the unveiling of a Jackson Pollock painting: much fanfare and anticipation, but what do all those strokes and blotches mean? This is narrative obliterated by action, the imaginary buried under the banality of the real.

These American and Chinese signals appear, each on its own merits, to have failed to deliver an outcome that might typically be thought of as "strategic." They are at best ambiguous with respect to the advancement of particular interests, seem to be uninterpretable according to Axelrod's maxims, and do not conform in any obvious way with the notion of leverage applied in order to re-establish an equilibrium of exchange. What connects these understandings of strategy, and what these authors ultimately bemoan for its absence, is symmetry, in one form or another. The signals exchanged between the US and China at least in this instance, are on the face of it entirely asymmetrical, both internally and in relation to each other, and so inspire puzzlement and frustration in their observers.

A strategic understanding of these signals requires that they be considered as of a piece; it is true, as these commentators suggest, that they are undecipherable as separately considered manoeuvres. The smallest investigable unit from a strategic perspective must be the action-reaction dyad, or more succinctly, the interaction. When considered as an exchange of behaviours, the fundamental property of the interaction is asymmetry, as I hope to have shown above ("Exchange relationships," pp. 34-38). What drives the exchange made possible by asymmetry is distrust, specifically strategic distrust as defined above (p.53), which is to deny the other's attempt to dissolve the real-imaginary boundary, while attempting a similar erasure of one's own.

The Chinese response to this US action serves, then, to dredge up the imaginary, to establish a narrative context that frames the Lassen's passage as anything but inno- 
cent, putting the lie to American claims of impartiality over sovereignty and attachment to a rules-based order. Moreover, in keeping with its own attempt to submerge the real, the Chinese statement downplays the material effectiveness of the action, by referring primarily to the intent of such actions in general, and to the very general nature of the Chinese response that should be expected. For the US, while the FONOP was not only clearly a response to perceived excessive territorial claims as defined by its interpretation of UNCLOS, it was also an anticipation of the public Chinese reaction which, given the long period of telegraphing, could easily have been drafted (and perhaps even leaked) well before the US action. In its apparent simplicity, the act of sailing a ship directly from one point to another cuts neatly through imagined justifications for objection and offence, however steeped in history and past grievance, revealing with a single incision both the real emptiness of Chinese threats and the transparency of American motivations.

\section{Superficial symmetry, deep asymmetry}

In this way, each party offers to the other an opportunity for the expression of distrust, elaborated as an exchange of values according to which each defines its position with respect to the other, and thus establishes its interests. In accepting the proffered signal, the receiver simultaneously declines it by denying the terms under which it is presented and offers up its own signal. What marks this exchange as cooperative is the cost exacted when one's signal is accepted and the attempt to erase certain distinctions therefore denied; in the case cited here the cost is to credibility, for the Chinese of the Party's nationalist legitimacy, and for the Americans of the reputation for unambiguous commitment to principle. Gained by each is the prolongation of a sort of stable uncertainty in the South China Sea, allowing the US to hold that it is maintaining the status quo of hegemony in the region, and China to demonstrate that it is beginning to assert its dominance within the first island chain.

The asymmetry of these costs and gains is a function of the material conditions under which each state acts; it is arguable on this basis that the exchange examined here cost the US less but earned China more, and the evidence for or against this position would be drawn from interpretations of their historical, geopolitical and economic circumstances. The logical structure of the exchange, on the other hand, remains 
ostensibly symmetrical. However, this structure too is subject to the operations of strategic distrust, revealing deeper asymmetries.

The superstructure of symmetrical exchange, a tiny part of which is represented by the FONOP example, provides the field on which the game of cooperation and defection can play out in the formation and reformation of equilibria according to interactions at the boundaries of value systems, defined by interests. Patterns of behaviour within and between systems begin to emerge, feeding back into their motivating values, triggering compromises in some parts of the system, but reifying others, potentially to the point of brittle inflexibility, as described in an earlier section ("Strategic equilibrium," pp. 43-47). These behaviours include the generation of narratives that explain the relationships between values and actions; certain of those generated by less flexible parts of the system may become foundational myths that explain particular prejudices and constrain the range of available self-consistent responses to the actions and narratives of others. In any event, these behavioural patterns, which give rise to the stability and predictability so prized by states as beneficial to the maintenance of interests, must eventually become unsustainable in the face of mounting contradictions and ever-narrowing choices. These patterns will most frequently relate to relatively unimportant regions of the value system, but will on occasion involve more vital areas, and different areas particular to each system will have different capacities for absorbing stress. But each of these patterns will ultimately reach its culminating point on encountering some other behaviour, even one it has met before but can no longer accommodate.

At this point, gaps in explanatory narratives and beliefs begin to open, through which can be discerned the contradictory basis for actions whose validity had before gone, if not necessarily unquestioned, at least unchallenged in their fundamental underpinnings. Distrust begins where these gaps occur, allowing the gradual separation of the real from a subsuming imaginary. Far from invalidating the imaginary and its constructs in favour of a now ascendant real, distrust exposes the primary asymmetry between these functions that drive all interaction between value systems.

As noted, the culminating points of behavioural patterns are occurring all the time, and mostly to relatively trivial effect at the level of state interactions. Despite their inevitability, it is impossible to predict with any certainty precisely when they will occur, and difficult (though perhaps not quite impossible) to predict their importance 
when they do. Nevertheless, this formulation of the nature of state interactions provides a role for strategy. In the first instance, an example of a pattern of behaviour is identified as requiring further analysis and possible response. Any number of reasons may present themselves as justifying the choosing of such an example, and each reason, typically couched in terms of interests, will imply an explanation for the behaviour's occurrence or importance, or both. One or more of these explanations will be accepted as more or less likely, and may include the "official" reasons as and if provided by the actor. Acceptance is immediately contingent upon the exercise of distrust regardless of the actor and the apparent truthfulness of the explanation: as a communicative act it must involve an elision of the real-imaginary distinction, intentional or otherwise. Prising open this distinction to reveal the asymmetries driving the act will provide evidence to facilitate an evaluation of the relative fragility or robustness of the values expressed in the behaviour and their susceptibility to the culmination of the pattern.

The projected response, which will in all likelihood be subjected to similar scrutiny, must account for the values entailed in its enactment and their own susceptibilities. If it can be determined that certain of one's values will be in some way reinforced in a manner beneficial to the system by the continuation of the other's behaviour, or at least that the potential damage to them that might result from alternative courses of action would be more harmful, then the response and the explanation in which it is couched, implicitly or explicitly, will be intended to delay the culminating point of the other's trajectory, while similarly extending one's own. It will no doubt be hoped that the other's strategic calculus, when applied to this response, will enable a similar conclusion to be drawn, and a period of cooperative equilibrium may be instituted.

Note that the same reciprocal process is engaged in the generation of what may ultimately be determined to be a conflictual response, and that this determination has, in principle, relatively little to do with the intentions of the actor, especially if confronted with a strategically literate opponent. Indeed, attributions of intent are "merely" part of the explanatory packaging of either or both the action and the reaction to it, and will be distrusted whatever the truth of the situation. Some actions, like those of the American FONOP and Chinese statement in reaction, appear superficially to be conflictual, but in the sense of strategy outlined here, are on the contrary probably most usefully to be considered cooperative. It is probable that such apparent an- 
omalies are in part a result of a sort of "observer effect": the act of applying a strategic analysis becomes a component of the calculus, as does the anticipation of the other's analysis, and so on. It should be obvious that such a chain will have its own culminating point, further contributing to the uncertainty of the entire project.

A yet further complication, and always highly significant, but perhaps especially so in the context of the South China Sea, is the presence of other actors, including other claimants to the relevant patches of sea, local allies and adversaries, and actors in other geopolitical contexts for whom the actions of the US in particular, but also increasingly those of China, enter into their own strategic assessments. It is undoubtedly this baffling multitude of inputs that have motivated complaints from a seemingly endless stream of commentators regarding the lack of an American "grand strategy," from the time at least of the Clinton administration, but it is a charge levelled with almost monotonous regularity at Barack Obama, as evinced by even the most cursory internet search.

Daniel Drezner tells us that:

A grand strategy consists of a clear articulation of national interests married to a set of operational plans for advancing them. Sometimes, such strategies are set out in advance, with actions following in sequence. Other times, strategic narratives are offered as coherent explanations connecting past policies with future ones. Either way, a well-articulated grand strategy can offer an interpretative framework that tells everybody, including foreign policy officials themselves, how to understand the administration's behaviour (Drezner, 2011, p. 58).

Most of the time, Drezner continues, grand strategies do not matter to great-power politics, but "during times of radical uncertainty in international affairs," and needless to say, we are currently immersed in one of these periods, they "really do count," and essentially for the reasons provided in his definition (2011, p. 61). One such grand strategic narrative, unveiled within a few months after the publication of Drezner's article, was the "pivot to Asia" with which this thesis opened. What is missing from Drezner's comments, as from the majority of calls for the elaboration of grand strategy, is any coherent sense of an other or others with which the US is engaged in 
exchange, and without which there can be no strategy at all. This should be considered a symptom of the proliferation of such "others" that have come on the scene since the fall of the Soviet Union, too many examples to be constrained by a simple tale of American preeminence and freedom of action. The pivot narrative suffers from the same failure to account for others that are more than the passive objects of American activity, but it cannot, of course, be trusted to do so. To give a failing grade to a strategy on the basis of the stories told about it is to fail utterly to understand strategy's duplicitous nature. 


\section{Disconclusion: culminating point}

A grand strategy, conventionally defined as by Drezner, is strategy's conclusion, providing advance notice that strategy has overreached its culminating point and become little more than a plan. But the very point of strategy is to keep this point in suspension, just beyond reach, and to distrust those seductive narratives that appear to offer, or demand that we make, choices between cooperation and conflict, ally and adversary, diplomacy and war, success and failure. Interests, defined by the struggle in which they are always at stake, cannot be served by a strategy that would so abdicate its responsibility to be always in full cognisance of the other as to "marry" those interests to "operational plans."

In contrast, the concept of strategic interaction presented here may go some way towards providing a means by which to assess and respond to behaviour that cannot be reduced to planning. The drawing up of a plan implies a theory according to the precepts of which the plan is constructed. Strategic interaction is in this sense an atheoretical, or perhaps more correctly a pretheoretical concept, that takes as its object observed behaviour arising as a contingent effect of an irreducibly complex and shifting context. No theory derived from these observations, designed to predict in any meaningful way the future course of state interaction, could be expected to survive the next encounter except by chance. And so the next encounter must be approached in the same distrustful manner, giving rise to the "incoherence and inconsistency" in policy that Luttwak finds so necessary (1998, p. 27), and the grand strategists so infuriating. But this approach is incoherent only from a perspective framed by the subordination of action to narrative, from which vantage the well-wrought plan (operational or otherwise) risks becoming an end in itself, obscuring the interests it purports to serve. In maintaining a focus on (inter)action, motivating values remain at the forefront of analysis; this focus becomes overtly strategic precisely where interactions are motivated by interests found at the "bleeding edge" of value systems. Policy based on analysis of strategic interaction will be coherent, to the extent that this is a virtue, with respect to interests rather than the imaginary constraints of narrative.

It should be clear that this concept of strategic interaction could not form the basis of a normative model for Chinese-American relations, on the basis of which one might feel compelled to choose this future course of behaviour over that, or to lament 
past and present choices that have failed to further the realization of our hopes and expectations. Instead, the concept offers a means of grasping what is occurring before us in the flesh, while keeping a wary and distrustful eye on the imaginary constraints of theory and ideology. It is messy and deeply unsatisfying of our symmetry-seeking impulses, but it is in our interests to recognize when we are telling ourselves stories. 


\section{Reference list}

Allen-Ebrahimian, B., \& Ryan, F. (2015, Oct 27). 'Stop boasting and fight': Nationalist Chinese netizens are furious that their country didn't take military action against the U.S. in the South China Sea. Retrieved from https://foreignpolicy.com/ 2015/10/27/china-south-china-sea-nationalism-united-states-navy-lassen/

Axelrod, R. (1990). The evolution of co-operation. Harmondsworth: Penguin.

Ayson, R. (2013). Is minimal order enough? Hugh White's strategic parsimony. Security Challenges, 9(1), 17-26.

Chesters, J. (2016). Trends in economic growth and levels of wealth inequality in G20 nations: 2001-2013. Contemporary Social Science. Retrieved from http:/ /www.tandfonline.com/doi/full/10.1080/21582041.2016.1199891

Choi, T. (2015, Nov 3). Why the US Navy's first South China Sea FONOP wasn't a FONOP. Retrieved from http://cimsec.org/why-the-us-navys-first-south-china-seafonop-wasnt-a-fonop/19681

von Clausewitz, C. (1976). On war (M. Howard \& P. Paret, Trans. Indexed ed.). [Kindle version]. Retrieved from Amazon.com

Clinton, H. R. (2011). America's Pacific century. Foreign Policy, 189, 56-63. . (2012). Remarks at the U.S. Institute of Peace China conference. Retrieved from http://www.state.gov/secretary/20092013clinton/rm/2012/03/185402.htm

Coker, C. (2015). The improbable war: China, the United States and the continuing logic of great power conflict. Oxford: Oxford UP.

De Luce, D., \& McLeary, P. (2015, Oct 2). In South China Sea, a tougher U.S. stance. Retrieved from http://foreignpolicy.com/2015/10/02/in-south-china-sea-a-tougheru-s-stance/

Deibel, T. L. (2007). Foreign affairs strategy: Logic for American statecraft. [Kindle version]. Retrieved from Amazon.com

Deng, X. (1984). Building a socialism with a specifically Chinese character. Retrieved from http://en.people.cn/dengxp/vol3/text/c1220.html

Dixit, A., \& Skeath, S. (1999). Games of strategy. New York: Norton.

Drezner, D. W. (2011). Does Obama have a grand strategy? Why we need doctrines in uncertain times. Foreign Affairs, 90(4), 57-68. 
Glaser, B. S., \& Dutton, P. A. (2015, Nov 6). The U.S. Navy's freedom of navigation operation around Subi Reef: Deciphering U.S. signaling. Retrieved from http://nationalinterest.org/feature/the-us-navy's-freedom-navigation-operation-aroundsubi-reef-14272

Graham, E. (2015, Nov 4). Innocent passage: Did the US just fumble its South China Sea strategy? Retrieved from https://www.lowyinstitute.org/the-interpreter/innocent-passage-did-us-just-fumble-its-south-china-sea-strategy . (2015, Nov 9). USS Lassen and 'innocent passage': The devil in the details. Retrieved from https://www.lowyinstitute.org/the-interpreter/uss-lassen-and-innocent-passage-devil-details

Hachigian, N. (Ed.). (2014). Debating China: The U.S.-China relationship in ten conversations. [Kindle version]. Retrieved from Amazon.com.

Hayton, B. (2016, Sept 22). The modern origins of China's South China Sea claim. Retrieved from https://amti.csis.org/event-modern-origins-chinas-south-china-seaclaim-bill-hayton/

Hoffman, A. M. (2002). A conceptualization of trust in international relations. European Journal of International Relations, 8(3), 375-401.

Homans, G. C. (1958). Social behaviour as exchange. American Journal of Sociology, 63(6), 597-606.

Jervis, R. (1978). Cooperation under the security dilemma. World Politics, 30(2), 167-214.

Keohane, R. O. (2005). After hegemony: Cooperation and discord in the world political economy (2nd ed.). Princeton: Princeton UP.

Kissinger, H. A. (2012). On China. London: Penguin.

Kroeber, A. R. (2013). Xi Jinping's ambitious agenda for economic reform in China. Retrieved from https://www.brookings.edu/opinions/xi-jinpings-ambitious-agenda-for-economic-reform-in-china/

$\mathrm{Ku}$, J. (2015, Nov 4). The US Navy's 'innocent passage” in the South China Sea may have actually strengthened China's sketchy territorial claims. Retrieved from https://www.lawfareblog.com/us-navys-innocent-passage-south-china-sea-mayhave-actually-strengthened-chinas-sketchy-territorial

Kuhn, R. L. (2013, June 5). Xi Jinping’s Chinese dream. International Herald Tribune, p. 6. 
Kydd, A. H. (2005). Trust and mistrust in international relations. Princeton: Princeton UP.

Lampton, D. M. (2013). A new type of major-power relationship: Seeking a durable foundation for U.S.-China ties. Asia Policy, 16, 51-68.

Lepgold, J., \& Shambaugh, G. (1998). Rethinking the notion of reciprocal exchange in international negotiation: Sino-American relations, 1969-1997. International Negotiation, 3(2), 227-252.

Lieberthal, K., \& Wang, J. (2012). Addressing U.S.-China strategic distrust (John L. Thornton China Center Monograph Series, No. 4). Washington, D.C.: Brookings Institution.

Lu, K. (2015, Oct 27). Foreign Ministry spokesperson Lu Kang's regular press conference on October 27, 2015. Retrieved from http://www.fmprc.gov.cn/mfa_eng/ xwfw_665399/s2510_665401/2511_665403/t1309625.shtml

Luo, X. (2016, July 19). The South China Sea case and China's new nationalism. Retrieved from http://thediplomat.com/2016/07/the-south-china-sea-case-and-chinasnew-nationalism/

Luttwak, E. N. (1998). Why we need an incoherent foreign policy. The Washington Quarterly, 21(1), 21-31.

- (2001). Strategy: The logic of war and peace (Rev \& enlarged ed.). Cambridge, MA: Belknap.

Magnier, M. (2016, April 15). China eases growth slide with debt-driven spending. Wall Street Journal. Retrieved from http:/www.wsj.com/articles/china-growthslows-revival-policies-appear-to-gain-traction-1460687389

Martina, M., \& Lim, B. K. (2016, Oct 27). China's Xi anointed “core” leader, on par with Mao, Deng. Retrieved from http://www.reuters.com/article/us-china-politicsidUSKCN12R1CK

Mearsheimer, J. J. (2014). The tragedy of great power politics. [Kindle version]. Retrieved from Amazon.com

von Neumann, J., \& Morgenstern, O. (2004). Theory of games and economic behavior (60th-anniversary ed.). Princeton NJ: Princeton UP.

Obama, B. (2011). Remarks by President Obama to the Australian Parliament. Retrieved from http://www.whitehouse.gov/the-press-office/2011/11/17/remarkspresident-obama-australian-parliament 
Obama, B., \& Xi J. (2013, June 8). Remarks by President Obama and President Xi Jinping of the People's Republic of China after bilateral meeting. Retrieved from https://www.whitehouse.gov/the-press-office/2013/06/08/remarks-president-obama-and-president-xi-jinping-peoples-republic-china-

Oye, K. A. (1985). Explaining cooperation under anarchy: Hypotheses and strategies. World Politics, 38(1), 1-24.

Palmerston, Viscount. (1848). Treaty of Adrianople - Charges against Viscount Palmerston. Hansard Commons Sitting, 97, cc. 66-123. Retrieved from http:/ /hansard.millbanksystems.com/commons/1848/mar/01/treaty-of-adrianoplecharges-against

Panda, A. (2015, Oct 28). Lassen faire in the South China Sea: Takeaways from the first US FONOP. Retrieved from http://thediplomat.com/2015/10/lassen-faire-inthe-south-china-sea-takeaways-from-the-first-us-fonop/

Rapp-Hooper, M. (2015, Oct 12). All in good FON: Why freedom of navigation is business as usual in the South China Sea. Retrieved from https://www.foreignaffairs.com/articles/united-states/2015-10-12/all-good-fon

Schelling, T. C. (1980). The strategy of conflict (2nd ed.). Cambridge, MA: Harvard UP.

Shalal, A., \& Brunnstrom, D. (2015, Oct 26). U.S. Navy destroyer nears islands built by China in South China Sea. Retrieved from http://www.reuters.com/article/ussouthchinasea-usa-idUSKCNOSK2AC20151026

Tiezzi, S. (2015, Sept 22). The truth about US freedom of navigation patrols in the South China Sea. Retrieved from http://thediplomat.com/2015/09/the-truth-aboutus-freedom-of-navigation-patrols-in-the-south-china-sea/

U.S. Department of Defense. (2015). U.S. Department of Defense freedom of navigation program: Fact sheet. Retrieved from http://policy.defense.gov/Portals/11/Documents/gsa/cwmd/DoD\%20FON\%20Program\%20-\%20Fact\%20Sheet\%20(March\%202015).pdf

U.S.-China Bi-National Commission on Trust-Building and Enhancing Relations. (2014). Building U.S.-China trust through next generation people, platforms \& programs. Annenberg, CA: USC US-China Institute. Retrieved from http://uschinaexchange.usc.edu/sites/default/files/us-china-trust-2014.pdf 
Varrall, M. (2015). Chinese worldviews and China's foreign policy (Lowy Institute Analyses). Sydney: Lowy Institute. Retrieved from https://www.lowyinstitute.org/ sites/default/files/chinese-worldviews-chinas-foreign-policy_0.pdf

Weiss, J. C. (2014, Nov 25). Chinese nationalism: The CCP's “double-edged sword". Retrieved from http://thediplomat.com/2014/11/chinese-nationalism-the-ccpsdouble-edged-sword/

White, H. (2013a). The China choice: Why we should share power. Oxford: Oxford UP.

. (2013b). Response to commentary on The China choice. Security Challenges, 9(1), 43-49.

World Bank. (2016). China. Retrieved from http://data.worldbank.org/country/china?view $=$ chart 